\title{
Realistic Energy Commitments in Peer-to-Peer Transactive Market with Risk Adjusted Prosumer Welfare Maximization
}

\author{
Vivek Mohan $^{1 *}$, Siqi Bu ${ }^{2}$, Jisma $\mathrm{M}^{1}$, Rijinlal VC ${ }^{1}$, Karthik Thirumala ${ }^{1}$, Mini Shaji Thomas ${ }^{1}$, Zhao Xu ${ }^{2}$ \\ ${ }^{1}$ Department of Electrical and Electronics Engineering, National Institute of Technology \\ Tiruchirappalli, Tamilnadu, India \\ ${ }^{2}$ Department of Electrical Engineering, The Hong Kong Polytechnic University, Hong Kong \\ *Email: vivekmohangokulam@gmail.com, vivekmohan@nitt.edu
}

\begin{abstract}
As the local energy sources are mostly uncertain and fluctuating in nature, the 'energy risk' due to discrepancies between committed energy transactions and metered measurements is prominent in peer to peer $(\mathrm{P} 2 \mathrm{P})$ markets. We propose a $\mathrm{P} 2 \mathrm{P}$ market settlement mechanism which lowers this risk and maximizes the welfare of buyers and sellers. The risk in energy production is modeled using Markowitz portfolio theory and the best point where energy return per unit risk is maximum is obtained from the efficient frontier by using the modified Sharpe ratio. The energy portfolio thus obtained is used as a constraint while optimizing the conflicting prosumer benefits using multi-objective stochastic weight trade-off chaotic non-dominated sorting particle swarm optimization (SWTC-NSPSO). In effect, only a reliable proportion of total energy demand submitted in the bid is cleared in the market, foreseeing the real-time fluctuations. The proposed market settlement mechanism also gives room to the existing distribution system operators by assigning them the duty of 1) optimally allocating energy among buyers and sellers in accordance with their competitive bids 2) providing the infrastructure, managing the market and charging for the service and 3) checking the technical feasibility by performing load flow and monitoring power transfer sensitivities to encourage short distance transactions. The energy allocation is done in CIGRE LV benchmark microgrid with ten peers having solar and wind generation. The allocated energy is found to be closer to the metered measurements and hence the reserve cost is observed to be low.
\end{abstract}

Keywords-Peer-to-peer, transactive energy market, portfolio, risk, multi-objective optimization, PSO

\section{Acronyms}

BFS

Backward Forward Sweep

DER

Distributed Energy Resources

DSO

Distribution System Operator 
Mean Absolute Deviation

MAPE

Mean Absolute Percentage Error

$\mathrm{MCP}$

Market Clearing Price

MNRE

Ministry of New and Renewable Energy

P2P

Peer-to-Peer

PTDF

Power Transfer Distribution Factor

RAWM

Risk Adjusted Welfare Maximization

RMSE

Root Mean Square Error

SEB

State Electricity Board

SWTC-NSPSO

Stochastic Weight Trade-off Chaotic Non-Dominated Sorting Particle Swarm Optimization

UoS

Use of Service charge

WM

Welfare Maximization

Nomenclature

$\mu_{p v}, \mu_{w}$

$\mu_{\Omega}$

$\sigma_{\Omega}$

C

$\boldsymbol{d}_{l}$

$\boldsymbol{E}_{\text {avl }}$

$E_{\text {com }}$

$E_{m e t, q}$

$E_{b, j}, P_{b, j}$

$E_{D}, P_{D}$

$E_{g i}, E_{d i}$

$E_{g i}^{*}$

$E_{i j}, P_{i j}$

$E_{k}^{p v}, E_{k}^{w}$

$\boldsymbol{E}_{s, i}, \boldsymbol{P}_{s, i}$

$G_{p v}, G_{\text {wind }}$
Average hourly energy generation from solar and wind respectively

Hourly average energy output from the wind-solar portfolio $\boldsymbol{\Omega}$

Standard deviation of energy outputs from the wind-solar portfolio $\Omega$

Grid power price/tariff

Utilization charge of line $l$

Total generation from actual resource available at transaction time $\mathrm{t}$

Total local generation committed at time $\mathrm{t}$

Metered generation of $\mathrm{q}^{\text {th }}$ sample at time $\mathrm{t}$

Energy and power transacted by $\mathrm{j}^{\text {th }}$ buyer

Total energy and power demand met during transaction time slot $\mathrm{t}$

Generation and demand of $i^{\text {th }}$ peer in offer/bid

Optimal local generation of $i^{\text {th }}$ peer

Committed energy and power transfer between $i^{\text {th }}$ seller and $j^{\text {th }}$ buyer

Energy generation in $\mathrm{k}^{\text {th }}$ minute from solar and wind respectively

Surplus energy and corresponding power transacted by $\mathrm{i}^{\text {th }}$ seller

Total solar and wind generation submitted in the offer/bid 
$I_{\text {node }}$

$m$

$\operatorname{MCP}_{p 2 p}$

n

$\boldsymbol{n}_{\boldsymbol{d}}$

$n F 1$

$\boldsymbol{n}_{\text {pop }}$

$N_{l}$

$N_{o b j}$

$P_{\text {grid }}$

$P_{\text {loss }}$

$\boldsymbol{P l o s s}_{i j}$

$\operatorname{Pr}_{s, i}, \operatorname{Pr}_{b, j}$

$P_{l}$

$P T D F_{x y}^{l}$

$R M_{1}$

$\mathrm{RM}_{2}$

$R M_{3}$

$S, B$

$S_{\text {node }}$

$\boldsymbol{t}_{\boldsymbol{d}}$

$\boldsymbol{U}_{j}\left(\boldsymbol{E}_{b, j}\right)$

$U_{o S_{i j}}$

$V_{\text {node }}$

$w_{p v}, w_{w}$

$\boldsymbol{w}_{\boldsymbol{p} v}^{*}, \boldsymbol{w}_{\boldsymbol{w}}^{*}$

$W_{\text {buyers }}$

$W_{\text {sellers }}$

$\boldsymbol{W}_{\boldsymbol{u}}$
Nodal current injection

Total number of historical minute-wise average generation data

Market Clearing Price (MCP) in P2P market

Number of uncertain samples

Total number of peers

Number of particles in non-dominated front

Number of particles generated in SWTC-NSPSO

Number of distribution lines

Number of objective functions

Power transacted with grid

Total active power loss in the network

Active power loss due to power transfer from $\mathrm{i}^{\text {th }}$ seller to $\mathrm{j}^{\text {th }}$ buyer

Welfare of $\mathrm{i}^{\text {th }}$ seller and $\mathrm{j}^{\text {th }}$ buyer respectively

Active power flow in line $l$

Power Transfer Distribution Factor of $l^{\text {th }}$ line due to transaction between $\mathrm{x}^{\text {th }}$ node and $\mathrm{y}^{\text {th }}$ node

Risk index derived from Mean Absolute Percentage Error

Risk index derived from Mean Absolute Deviation

Risk index derived from Root Mean Square Error

Total number of sellers and buyers respectively

Nodal complex power injection

Duration of energy transaction in hours

Utility function representing satisfaction level of $\mathrm{j}^{\text {th }}$ buyer

Use of service charge for energy transfer from $i^{\text {th }}$ seller to $\mathrm{j}^{\text {th }}$ buyer

Nodal voltage

Proportion of solar and wind generation from the total

Optimum weights that maximizes modified Sharpe ratio

Total welfare of buyers

Total welfare of sellers

Membership function for $\mathrm{u}^{\text {th }}$ objective function 
$\boldsymbol{W}_{\boldsymbol{o b j}, \boldsymbol{u}}^{\min }, \boldsymbol{W}_{\boldsymbol{o b j}, \boldsymbol{u}}^{\max } \quad$ Minimum and maximum values of $\mathrm{u}^{\text {th }}$ objective function in non-dominated front

$W^{v}$

Function used for selection of optimum particle

\section{Introduction}

Power networks are under a transition from passive distribution systems to active ones with the penetration of local energy sources. Thus, modern-day consumers have become prosumers by which they satisfy their own demand and with the surplus, they either give back to the grid or deliver to one or more peers. Consequently, local energy trading among peers subscribed to a common market framework is encouraged, leading to a P2P transactive environment [1] - [3]. To facilitate this framework, local energy networks incorporate bidirectional power flow and smart metering, information \& communication technology, cyber-physical interaction, decentralized control [4] and trading platforms [5]. These technologies cater to attain different social, environmental and technical objectives based on 1) extent of liberalization of the market in the country of deployment and 2) type of energy sources contained in the system. The local generation is predominantly from renewable energy sources and hence the effect of their uncertainties on the aforementioned objectives have to be discussed in detail. Hence, the review of literature is organized into two groups: 1) Modelling risk and 2) Microgrid prosumer consortium.

Modelling Risk: Regardless of the type of the market framework, optimal energy planning is essential in the preinstallation and pre-operational time horizons considering financial and technical risks involved in it. Risks due to different sources of uncertainties are modelled in the literature. Financial risk of the operator due to uncertainties in renewable generation is modelled using affine arithmetic in [6]. The same risk is modelled as the measure of 'profit per unit risk' using Sortino ratio in [7]. However, the authors focused only on the market model 'DSO-Monopoly', where the risk and return were defined in respect of the system operator only. In [8], the effect of fuel price variations on the cash flow risk of GenCo is studied using artificial neural networks. Risk in operational cost due to uncertainties in wind speed and dependence of multiple wind farms in economic dispatch problems using the mean-variance model is discussed in [9]. In [10], income risk on GenCos due to spot price fluctuations and component failures is modelled using bi-level optimization. Simulation of market behaviour with changing bidding strategies and its effect on GenCo's benefit is modelled using conditional value at risk $(\mathrm{CVaR})^{-}$in [11]. In summary, the aforesaid literature modelled return and risk in terms of financial quantities and were restricted to a single stakeholder. Also, the risk in allocated energy and corresponding welfare in the P2P market due to temporal and spatial variations of renewable energy is unexplored.

Microgrid Prosumer Consortium: Another body of literature focused on a more liberalized market model, the prosumer consortium, where the technical and economic challenges posed by the active distribution networks were addressed by framing a suitable localized market. Several such frameworks including P2P transactions are put forward based on individual and collective welfare, giving rise to new settlement procedure [12], bidding mechanisms [13] and [14], ancillary services market [15], energy management and optimization algorithm [16] etc. However, [12], [13] and [15] did not consider network feasi- 
bility, [16] was silent about collective benefits and all of them discarded the conflicting nature of profits. On the other side, there is a moving trend towards decentralized markets with distributed ledger and Blockchain technologies, eliminating the third party for improving security and transparency [17] and [18]. A P2P-ready consensus-based distributed algorithm that fully discards the role of the central controller and fully compatible to prosumer preferences, for economic operation of distribution grid is proposed in [19] and [20]. Authors in [17] - [22] viewed the P2P market from prosumers' perspective only, without considering operators' technical preferences. In contrast to the above propositions, some of the recent papers dealt with network constraints also, using sensitivity factors and line flow constraints [23], [24]. Still, an attempt is not made in any of the papers to narrow down the gap between committed and metered energy transactions of peers by modelling risk and return in terms of energy $(\mathrm{kWh})$. In addition, there are contextual challenges with respect to the scale and coverage of deregulation in the country where P2P transactive energy market is envisaged, which is discussed in the following paragraph.

Challenges in Indian Scenario: In a semi-deregulated environment like India [25], [26], the responsibility of meeting the network constraints combined with the enhancement of prosumer benefits should be ideally taken care of by the existing operator/third party. In India, the distribution of power at low voltage levels is largely done by state electricity boards (SEBs). However, The Ministry of New and Renewable Energy (MNRE) has proposed various business models where grid-connected solar panels can be either fully owned by a consumer or owned, operated and maintained by the utility. By this, the consumer can feed to the grid with his local generation and earn revenue through net metering or renting out his space for PV installations. Still, the consumers lack avenues for local energy trading among neighbours in the present scenario [27], [28]. Hence, the implementation of P2P transactions among the end consumers may not happen all at once, rather the SEBs may be given a different role in the newly designed transactional framework. However, as we move from conventional distribution systems to P2P market framework, too many short-term contracts/commitments targeting individual benefits/welfare would be involved. In such a framework, each market subscriber's sole objective would be to make commitments resulting in maximum profit. As a result, the committed energy transactions will not be in line with the metered measurements in real-time. The mismatch is more profound if the relied sources are renewable energy based.

To sum up, when targeting an individual or collective welfare, the contracted volume of energy (typically with renewable energy sources) may be far away from reality and hence the metered measurements would be largely deviating from the committed or cleared energy. Thus, the allocated energy may pose both financial and energy risk to the subscribers/operator based on reserve considerations. An optimal generation mix (different energy technologies in the right proportion) that minimizes the energy risk is thus essential for clearing the market depending on the location and time of availability of energy resources. At the same time, conflicting welfare of prosumers should be taken into consideration. In addition, the role of the existing operator/owner of the active distribution system cannot be totally discarded from a semi-deregulated viewpoint. Hence, they can serve as a service \& infrastructure provider and charge for it based on the network-congestion. Further, the 
final allocation should be network-feasible and contingent to the competitive bids/offers. In the forerunning context, this paper proposes an energy risk constrained welfare maximized P2P market settlement framework where the main contributions are as follows.

i. Finding the optimal energy portfolio for hourly market clearing using Markowitz mean-variance theory and modified Sharpe ratio which maximises the energy returns and minimizes the energy production risk due to lack of firmness in hourly generation. In effect, the risk due to the difference between committed and metered transactions in the P2P market is taken care of.

ii. Maximising the conflicting welfare of prosumers (sellers and buyers) using SWTC-NSPSO to determine the peer to peer energy allocation subject to the risk adjusted portfolio obtained in (i). That is, a reliable proportion of energy submitted in the bids/offers is only cleared in the market. The welfare function is designed by considering traded energy, network losses, buyers' comfort level and use of system and service charges.

iii. Checking the network feasibility by conducting backward-forward sweep load flow and thereby calculating the use of service (UoS) charge earned by the third party in accordance with the line flow sensitivities to encourage short distance transactions.

iv. The proposed market settlement is carried out in CIGRE LV benchmark microgrid with ten peers having solar/wind generation. The risk adjustment is validated using risk metrics derived from MAPE, MAD and RMSE.

The paper is organized as follows. The methodology is given in Section 2. Test system, results and discussions are described in Section 3. The paper is concluded in Section 4.

\section{Methodology}

The role and responsibility of the third party in conduction of the P2P market is shown in Fig.1. The trading starts with the submission of bids by prosumers which has the information on maximum local generation, load demand, desired selling and buying prices for the time period t. From the bids/offers submitted till time t-1, the third-party clears that proportion of load demand which can be met from the optimal solar-wind generation portfolio. Then, energy is allocated among sellers and buyers corresponding to their maximum traded-off welfare, subject to the network constraints, keeping the wind-solar mix intact. In real time, any deviation from the committed energy is met from the grid. The financial settlement for the traded energy is then processed within a month. 


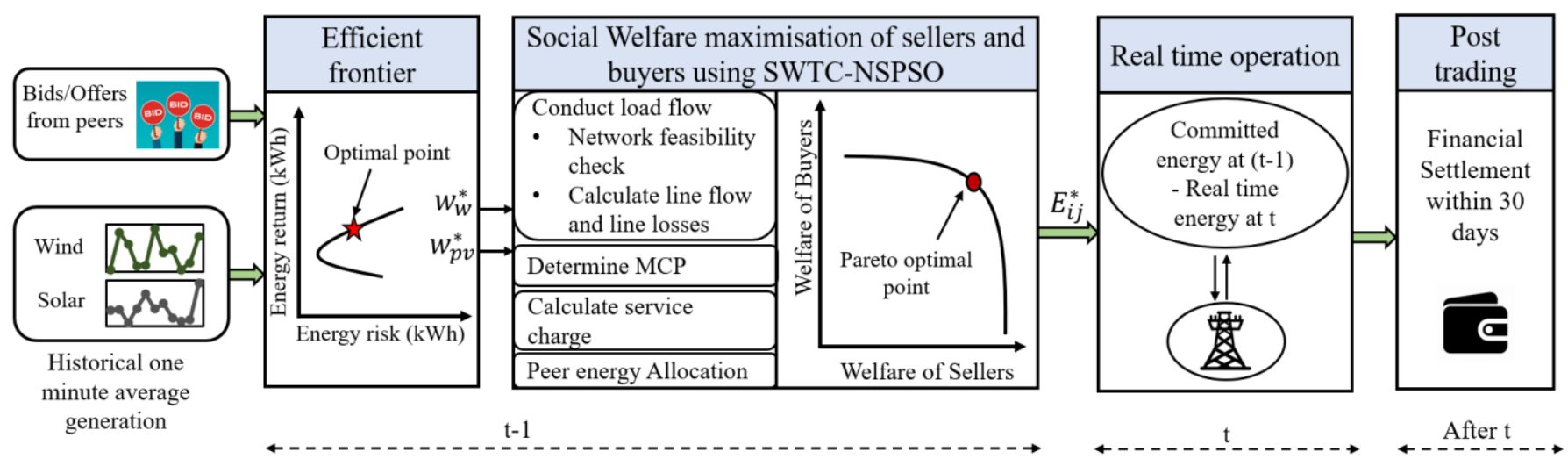

Fig. 1. The proposed P2P market settlement

\subsection{Processing bids and optimising energy portfolio}

The peers willing to participate in the trading hour $\mathrm{t}$ are allowed to submit offers/bids till gate closure (an hour prior to the actual trading). Let $\left(E_{g, i}, E_{d, i}\right.$, offer $/$ bid $\left._{i}\right)$ be the willingness submitted by the $\mathrm{i}^{\text {th }}$ peer where $E_{g, i}$ and $E_{d, i}$ represent the maximum possible generation and the load demand in $\mathrm{kWh}$ during time t. The terms offer ${ }_{i}$ and bid $_{i}$ represent the desired selling and buying prices respectively. As the peers are to be lured for P2P trading compared to the conventional (as per the existing monopolistic framework) grid power trade at tariffs/FiTs, the offer is kept higher than feed-in-tariff (FiT) and the bid is lower than the tariff.

In the hourly market, the committed energy by the prosumer prior to the actual transaction shall be a single-valued representation capturing the inherent temporal variations in energy production throughout the hour. This energy production risk is modelled using Markowitz mean-variance theory [29], [30]. The theory is used in finance to evaluate risk and return of investment portfolios. Here, instead of taking financially risky assets like stocks, bonds, mutual funds etc., into consideration, we take uncertain energy sources like wind and solar whose energy production is fluctuating and risky in nature. Hence, risk and return are represented in terms of energy. Now, the expected value of hourly energy output for various generation mix proportions is calculated to obtain the return of portfolio and the portfolio standard deviation represents the risk. The historical minute-wise average generation of the given sources for the month under consideration is used to model the energy production risk and return. $E_{k}^{p v}$ and $E_{k}^{w}$ represent the total energy produced at $\mathrm{k}^{\text {th }}$ minute by the PV and wind sources respectively. The expected hourly generation is then calculated using equations (1) and (2).

$$
\begin{gathered}
\mu_{p v}=\frac{1}{m} \sum_{k=1}^{m} E_{k}^{p v} \\
\mu_{w}=\frac{1}{m} \sum_{k=1}^{m} E_{k}^{w}
\end{gathered}
$$

The expected hourly energy return from the portfolio is calculated using equation (3) and the portfolio risk (standard deviation) is obtained using equation (4) where $w_{p v}, w_{w} \in[0,1]$ are the weights of solar and wind generation respectively. The matrix 
Cov represents the covariance between wind and solar generation. The efficient frontier as shown in Fig. 2 is then drawn by varying the weights, satisfying equation (5). For the same energy production risk level D in Fig. 2, the expected energy return is more for the upper part (point A) compared to the lower part (point B) of the curve. Hence, the upper portion (efficient frontier) of the curve is searched for the optimal point.

$$
\begin{gathered}
\mu_{\Omega}=w_{p v} \mu_{p v}+w_{w} \mu_{w} \\
\sigma_{\Omega}^{2}=\left[\begin{array}{cc}
w_{p v} & w_{w}
\end{array}\right][\mathrm{Cov}]\left[\begin{array}{l}
w_{p v} \\
w_{w}
\end{array}\right] \\
w_{p v}+w_{w}=1
\end{gathered}
$$

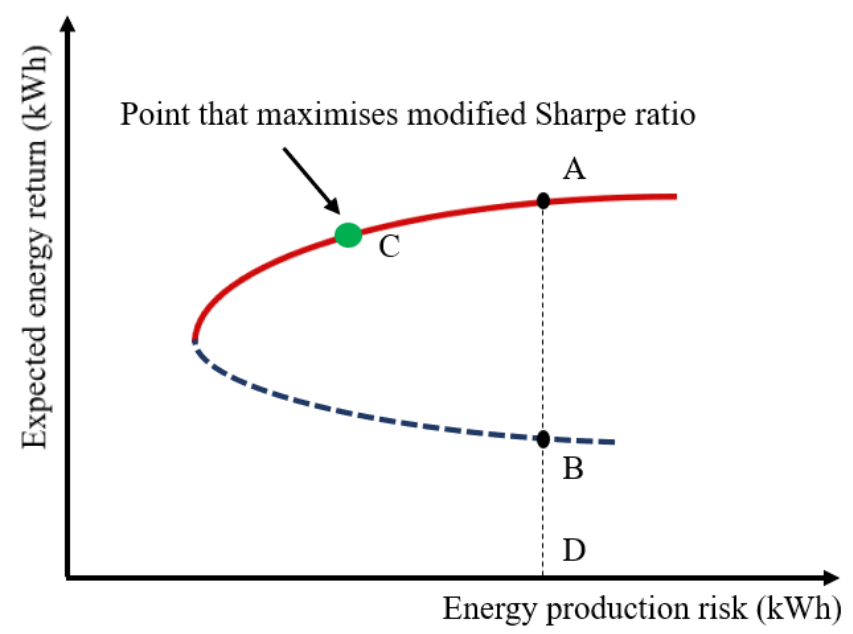

Fig. 2. Efficient frontier for expected energy return versus energy production risk

The total load demand submitted in the bid is fully or partially met from the optimal mix of solar-wind generation obtained from the efficient frontier as shown in equation (6). The best point from the efficient frontier is then selected by using the concept of Sharpe ratio. The Sharpe ratio in finance is a reward to variability ratio defined as excess return divided by the standard deviation of the returns where the excess return indicates portfolio return minus risk-free return. So, the portfolio with a higher Sharpe ratio gives better return for the same risk [31]. Here, in the modified Sharpe ratio, the 'excess' financial return in the numerator is replaced by expected portfolio energy return $(\mathrm{kWh})$ and the denominator represents the portfolio standard deviation (energy production risk). Maximization of modified Sharpe ratio results in an energy portfolio with maximum expected energy for unit risk. Hence, the optimal weights are obtained by maximizing the modified Sharpe ratio $\frac{\mu_{\Omega}}{\sigma_{\Omega}}$ using equation (7).

$$
\begin{gathered}
\underbrace{\left(w_{p v} \times G_{p v}\right)+\left(w_{w} \times G_{w i n d}\right)}_{E_{D}} \leq \sum_{i=1}^{n_{d}} E_{d i} \\
{\left[w_{w}^{*} w_{p v}^{*}\right]=\arg \left(\max \left\{\frac{\mu_{\Omega}}{\sigma_{\Omega}}\right\}\right)}
\end{gathered}
$$

A proportion $w_{w}^{*}$ of total energy demand $E_{D}$ is cleared from wind and $w_{p v}^{*}$ from solar. These weights serve as energy risk constraints in the P2P market settlement process. 


\subsection{Peer energy allocation}

From the bids and offers submitted by the peers, the power surplus/deficit available for trading is determined and the marketclearing price (MCP) is derived using double auction with average mechanism [24] as shown in equation (8).

$$
M C P_{p 2 p}=\frac{\sum_{i=1}^{S} \text { offer } i+\sum_{j=1}^{B} b_{i d}}{S+B}
$$

Now, the sellers are arranged in the ascending order of their offer prices and the buyers are arranged in the descending order of their bids. Then, energy allocation is done by the market operator, starting from the seller with the lowest offer (i=1) and the corresponding buyer with the highest bid $(\mathrm{j}=1)$, as shown in algorithm-1, satisfying the power balance constraints $E_{s, i}=$ $\sum_{j=1}^{B} E_{i j}$ and $E_{b, j}=\sum_{i=1}^{S} E_{i j}$

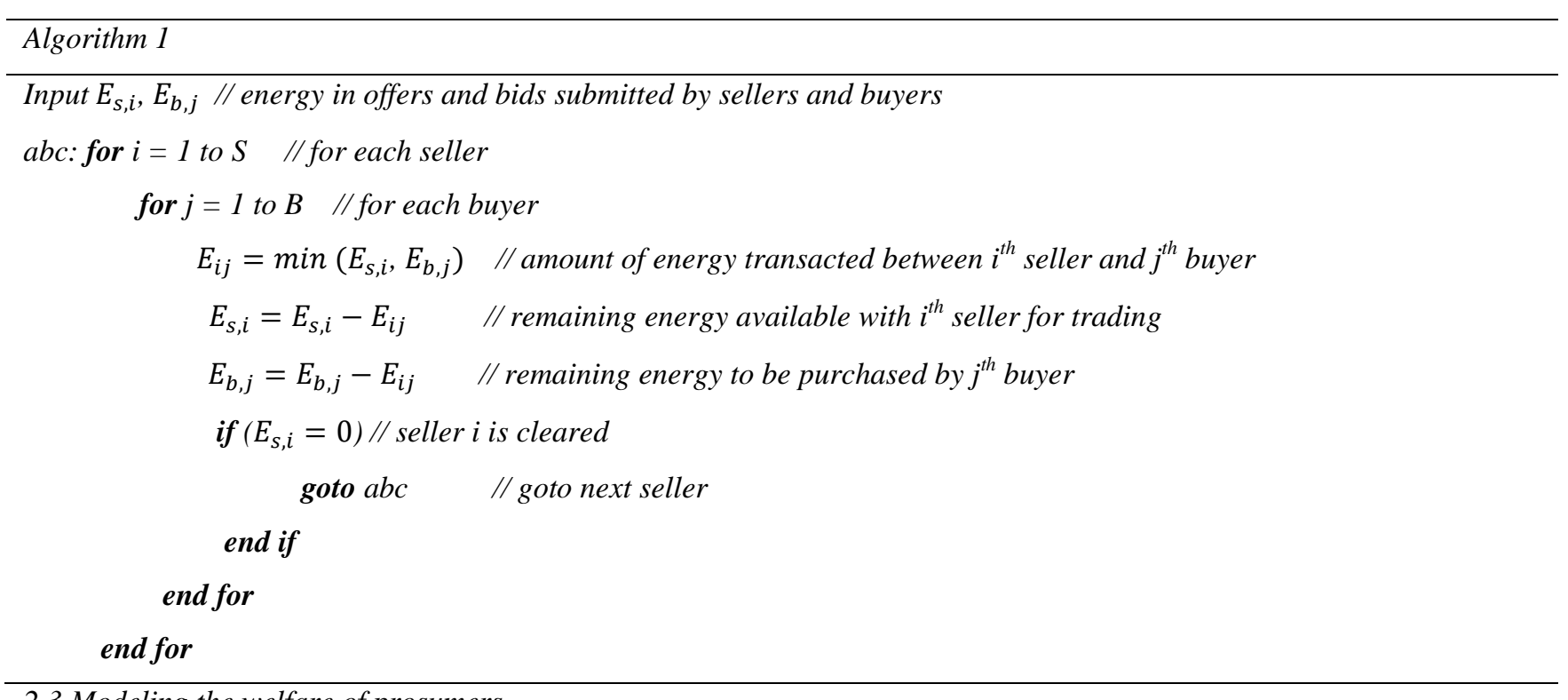

\subsection{Modeling the welfare of prosumers}

The P2P Energy transactions are not assumed to be one-to-one. The welfare of sellers and buyers are modelled as the difference between revenue and expense in equations (9) and (10) respectively. The seller earns revenue from the sale of surplus generation $\left(1^{\text {st }}\right.$ term of equation (9)) and the buyer's revenue is the monetary representation $\left(1^{\text {st }}\right.$ term of equation (10)) of his satisfaction level while consuming power. The response of the buyer for different amounts of power consumption at different time intervals and climatic conditions is modelled as a quadratic utility function satisfying properties related to consumer's choice [24], [32]. For every transaction between $i^{\text {th }}$ seller and $j^{\text {th }}$ buyer, they should pay UoS charge $\left(2^{\text {nd }}\right.$ term of equations $(9)$ and (10)) to the network owner/third-party for utilizing the distribution network and availing the service of managing the $\mathrm{P} 2 \mathrm{P}$ market. Also, an additional amount for network losses involved in the transaction is equally shared among buyer and seller $\left(3^{\text {rd }}\right.$ term of equations (9) and (10)). In contrast to the conventional passive distribution system where the network utilization charges are passed on to the buyer/end consumer, here, it is equally shared among the prosumers/producers/consumers in the active distribution network. Finally, the $4^{\text {th }}$ term of equation (10) represents the cost of power purchase at MCP. 


$$
\begin{aligned}
& P r_{s, i}=\left(M C P_{p 2 p} \times E_{s, i}\right)-\frac{1}{2}\left(\sum_{j=1}^{B} E_{i j} \times U o S_{i j}\right)-\frac{1}{2}\left(\sum_{j=1}^{B} \operatorname{Ploss}_{i j} \times C \times t_{d}\right) \\
& P r_{b, j}=U_{j}\left(E_{b j}\right)-\frac{1}{2}\left(\sum_{i=1}^{S} E_{i j} \times U o S_{i j}\right)-\frac{1}{2}\left(\sum_{i=1}^{S} \operatorname{Ploss}_{i j} \times C \times t_{d}\right)-\left(M C P_{p 2 p} \times E_{b, j}\right)
\end{aligned}
$$

The objective is to maximize the conflicting welfare (see equation (11)) of buyers and sellers. Hence, the problem is modelled as a multi-objective optimization problem where the optimum energy allocation trades off the welfare of sellers and buyers (see equations (12) and (13)).

$$
\begin{gathered}
\max \left\{W_{\text {sellers }}, W_{\text {buyers }}\right\} \\
W_{\text {sellers }}=\sum_{i=1}^{S} P r_{s, i} \\
W_{\text {buyers }}=\sum_{j=1}^{B} P r_{b, j}
\end{gathered}
$$

\subsection{Network feasibility check and calculation of service charge}

The network feasibility is checked by performing Backward Forward Sweep (BFS) load flow [33] during the energy allocation process, satisfying the voltage and power balance constraints as shown in equations (14) and (15) respectively. The generation and demand at each node is updated for every update of allocated energy. The major steps involved are as follows.

1) Input line data and $P_{i j}$

2) Initialize the bus voltages with $1 \mathrm{p} . \mathrm{u}$.

3) Update power injections at seller node $\mathrm{x}$ and buyer node $\mathrm{y}$ for every transacted power $P_{i j}$; +ve for buyer node and -ve for seller node

4) Calculate branch currents from nodal current injections, $I_{\text {node }}=\left(\frac{s_{\text {node }}}{V_{\text {node }}}\right)^{*}$

5) Update nodal voltages through forward sweep.

6) Repeat steps (4) and (5) until tolerance limit is reached.

$$
\begin{gathered}
V_{\text {node }}^{\min } \leq V_{\text {node }} \leq V_{\text {node }}^{\max } \\
w_{p v}^{*} P_{D}+w_{w}^{*} P_{D}+P_{\text {grid }}=P_{D}+P_{\text {loss }}
\end{gathered}
$$

The use of service charge for a transaction from $\mathrm{i}^{\text {th }}$ seller to $\mathrm{j}^{\text {th }}$ buyer is calculated using the Power Transfer Distribution Factor (PTDF) [24] as shown in equation (16).

$$
U o S_{i j}=\sum_{l=1}^{N_{l}} \frac{P T D F_{x y}^{l} \times d_{l}}{P_{l}}
$$


Where, $d_{l}$ and $P_{l}$ are the utilization charge and the total power flow in the line $l$, respectively. The term $P T D F_{x y}^{l}$ represents the change in active power in line $l$ due to a transaction from seller node $x$ to buyer node y. The $P T D F_{x y}^{l}$ takes the value zero if the line $l$ is not involved in the transaction. For every new energy allocation/transaction, the new line flows corresponding to updated nodal power injections are calculated using BFS load flow.

\subsection{SWTC-NSPSO based welfare maximization}

The variation of welfare of buyers with respect to optimization of sellers' welfare is shown in Fig.3. As the objectives are found to be conflicting in nature, multi-objective SWTC-NSPSO is used to find the pareto-optimal solution.

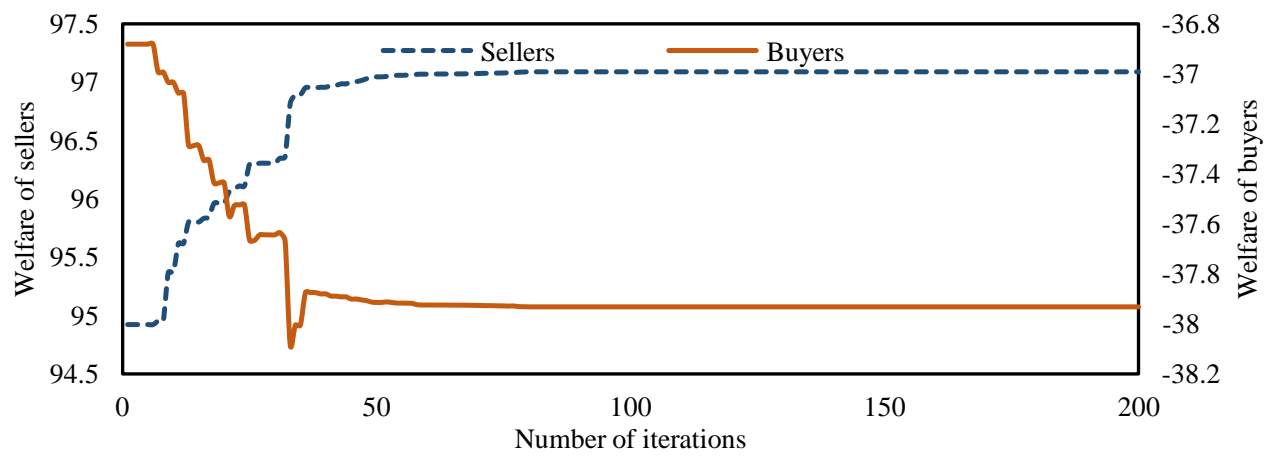

Fig. 3. Variation of welfare of buyers with welfare of sellers

Although the maximum local energy that can be generated is included in the willingness submitted by the peers $\left(E_{g i}\right)$, it is updated to the optimal value $E_{g, i}^{*}$ after maximizing the welfare subject to energy constraints i.e., peer power generation is the decision variable contained in the particle vector. Fig.4. shows energy corresponding to bid/offer values, optimal local generation and the final commitment in the market. $\left(E_{g i}^{*}-E_{d i}\right)$ and $\left(E_{d i}-E_{g i}^{*}\right)$ are the final commitments of seller and buyer in the P2P market respectively.

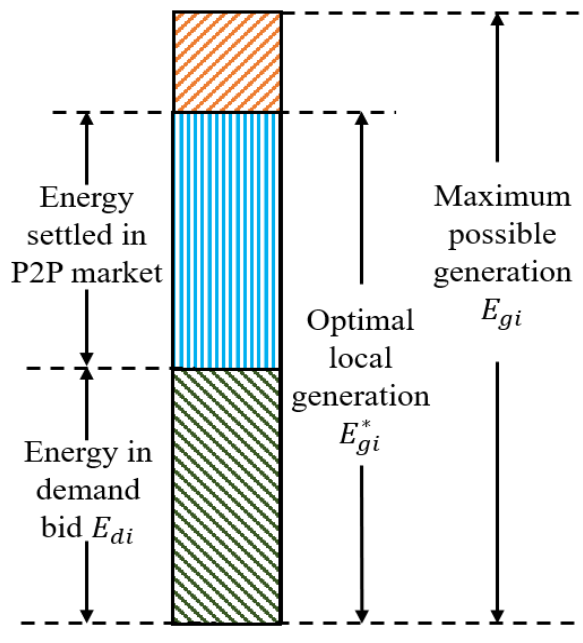

For seller

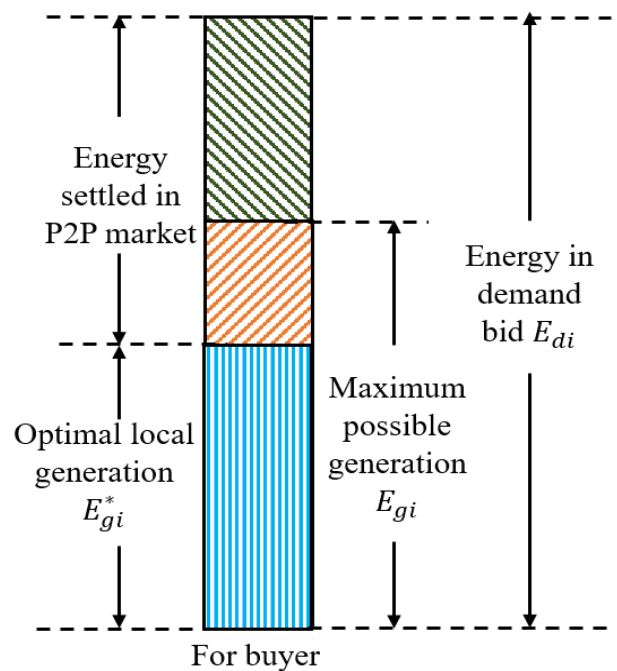

For buyer

Fig. 4. Energy in bid/offer, optimal local generation and committed transaction in $\mathrm{P} 2 \mathrm{P}$ market for seller and buyer 
In normal PSO, the velocity and position of the particles are updated to streamline the search for global optimum. Still, there are instances where the solution is trapped in the local optima due to premature convergence and paucity of global best exploration or/and local best utilization. To avoid this, stochastic weight trade-off and chaotic mutation technique involving freak and lethargy factors are incorporated in SWTC-NSPSO [34] [35] by diversifying the search. Also, the swarm members are prioritized in descending order of crowding distance (See Fig. 5 (a)) in each iteration to obtain the local best-compromised solutions. Further, it is empirically observed that the pareto front is widened when the chaotic mutation technique is used over normal NSPSO in multi-objective optimization. This gives a larger search space for selection of the best candidate satisfying the maximum value of Sharpe ratio given in equation (7).

$$
\begin{aligned}
& W_{u}=\left\{\begin{array}{cc}
0 & W_{o b j, u}=W_{o b j, u}^{\min } \\
\frac{W_{o b j, u}^{\max }-W_{o b j, u}}{W_{o b j, u}^{\max }-W_{o b j, u}^{\min }} & W_{o b j, u}^{\min }<W_{o b j, u}<W_{o b j, u}^{\max } \\
1 & W_{o b j, u}=W_{o b j, u}^{\max }
\end{array}\right. \\
& W^{v}=\frac{\prod_{u=1}^{N_{o b j}} W_{u}^{v}}{\sum_{v=1}^{n F 1} \sum_{u=1}^{N_{o b j}} W_{u}^{v}}
\end{aligned}
$$

The normalized variable values of $\mathrm{u}^{\text {th }}$ welfare, $W_{u}$ ranges from 0 to 1 as the objective value in the pareto front moves from minimum to maximum (See equation (17)). Then, from the pareto optimal front (See Fig. 5 (b)) the global best-compromised solution is found from equation (18), which represents the measure of trade-off among welfares 1 and 2 . That is, the higher the value of $W^{v}$, better the solution is. The best (trade-off) point in the front corresponds to the particle with maximum value in the numerator of equation (18), which is located roughly around the midpoint of the front. The extreme ends of the pareto front (greater importance to either buyer/seller) yields a lower value of numerator and thus can be avoided. In general, the ratio given in Equation (18) yields a higher value when the collective welfare is high (better trade-off) and it gives a lower value when either of the

objectives dominates too much.

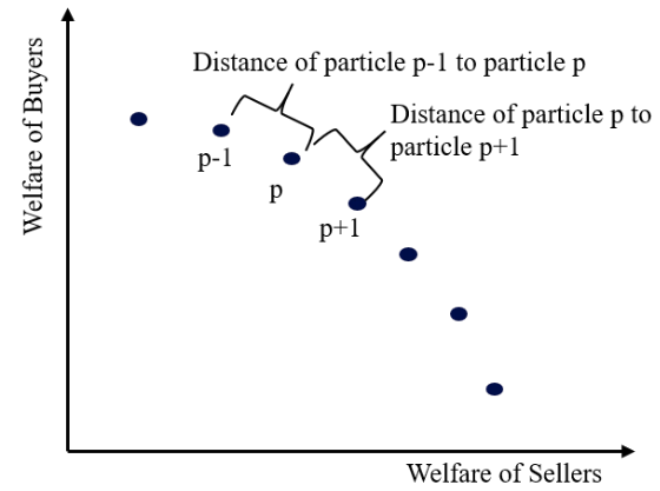

(a)

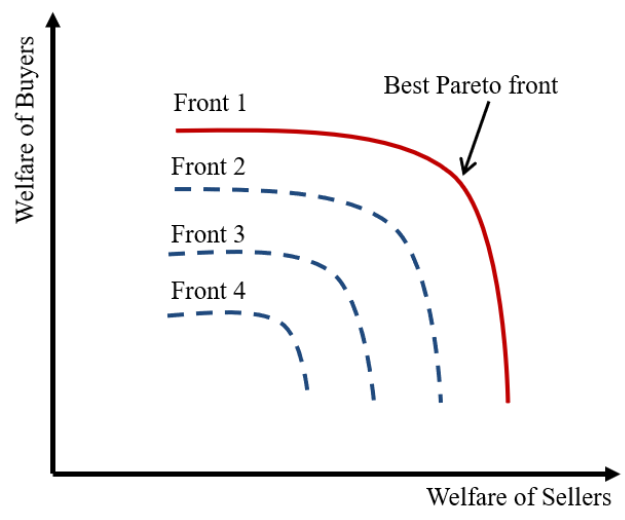

(b)

Fig. 5(a) Crowding distance calculation

Fig. 5(b) Non-dominated sorting concept 
The major steps involved in the SWTC-NSPSO based welfare optimization is shown in Algorithm-2.

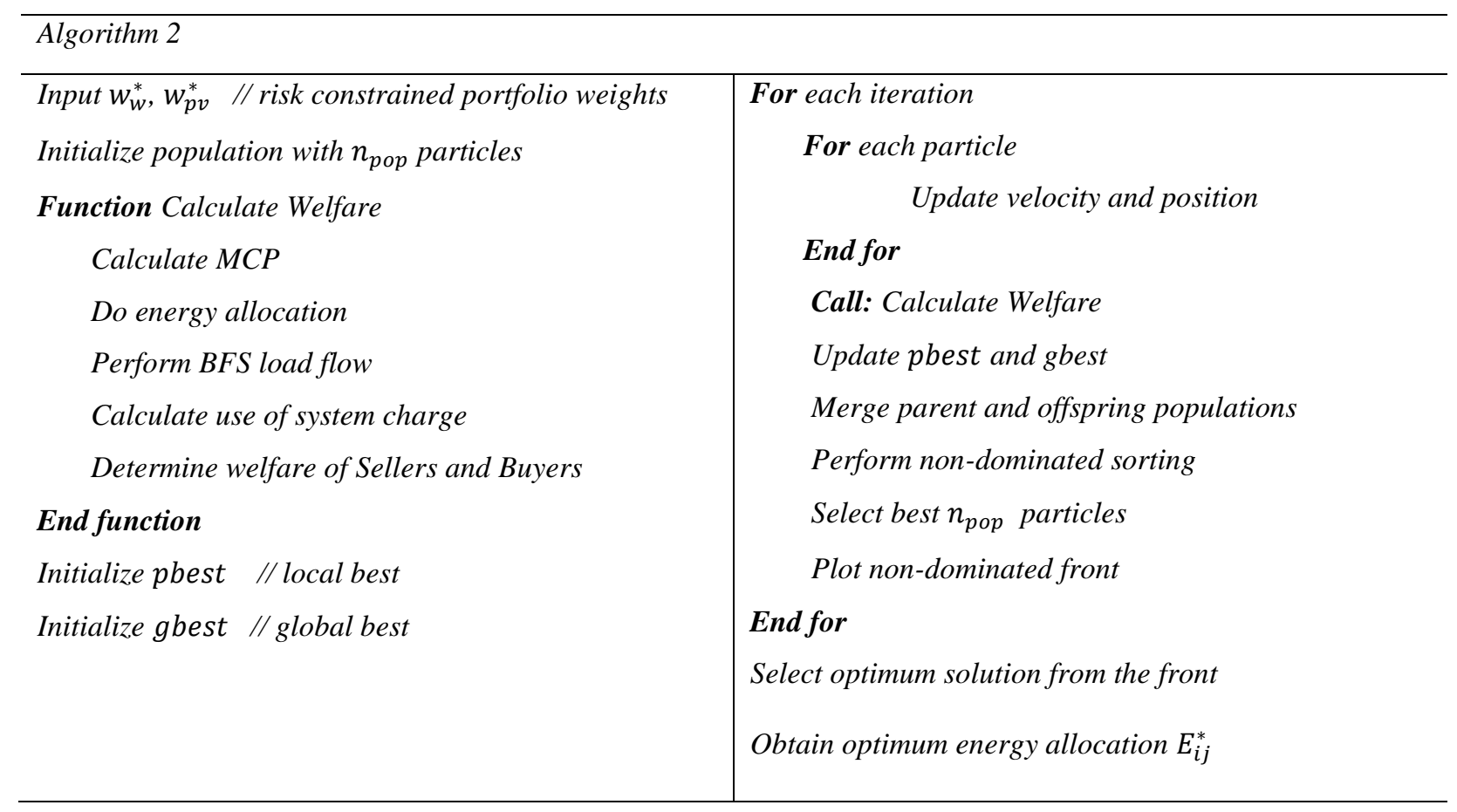

\subsection{Energy risk adjusted P2P market settlement}

The flowchart for the overall procedure for the energy risk adjusted P2P market settlement is given in Fig.6. The process of energy trading in the P2P market is divided into four phases. In the first phase (till t-1), the offers and bids are submitted by the peers and the optimum share of wind and solar energy for minimizing the real-time deviations of committed energy is determined from the historical generation data using Markowitz mean variance theory and modified Sharpe ratio. In the second phase (t-1 to t), optimum peer energy is allocated by trading-off the welfare of buyers and sellers using SWTC-NSPSO. During the allocation process, the market clearing price is determined from the submitted bids, energy is allocated based on how competitive bids and offers are, load flow is executed to find the energy losses as well as to check the network feasibility, the welfare of prosumers is then calculated and thus the committed energy of each peer is determined. In the third phase (at transaction time, $\mathrm{t}$ ), any deviation from the committed energy is settled by the grid. The reserve cost/revenue for the deviation is calculated at the grid power price and it is shared among the buyers/sellers in proportion to their individual share. The financial settlement of the energy transacted in the P2P market as well as from the grid is then done by the SEBs in the fourth phase (after time t). 


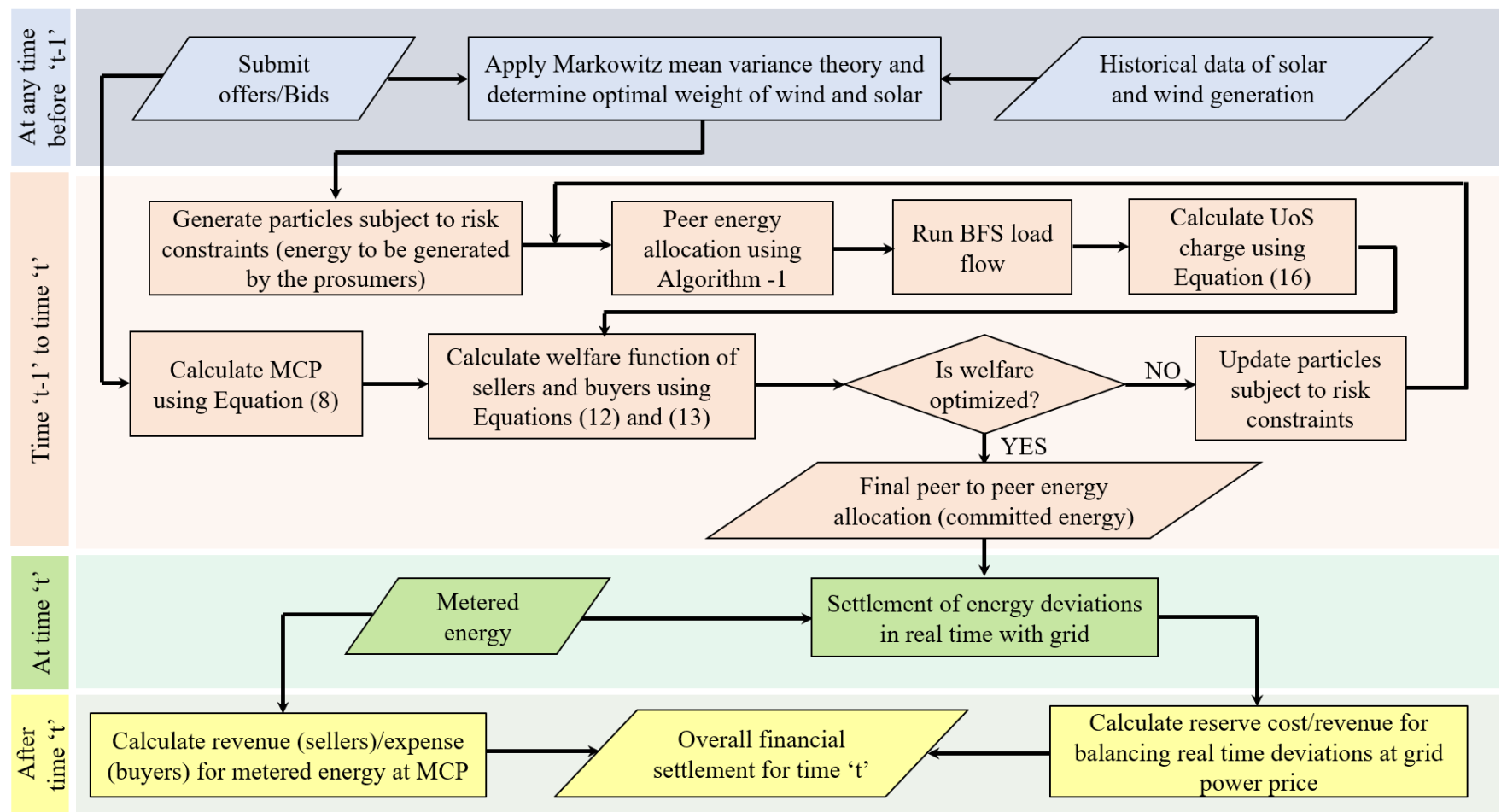

Fig. 6. Flow chart for energy risk adjusted P2P market settlement

\subsection{Metrics for validating energy risk}

Let $E_{a v l}$ be the maximum energy that can be generated during the actual transaction period in accordance with the resource availability. If $E_{a v l}$ is greater than or equal to the committed energy generation $\left(E_{c o m}\right)$, then the metered measurement is considered to be equal to $E_{c o m}$ else, the metered energy is equal to $E_{a v l}$. That is, the scenarios in which $E_{a v l}$ is less than $E_{c o m}$ are considered to be 'risky'. To validate the risk in deviation of metered energy measurements from the committed transactions, the metrics $R M_{1}, R M_{2}$ and $R M_{3}$ are used as shown in equations (19), (20) and (21). These indices are derived from Mean Absolute Percentage Error (MAPE), Mean absolute Deviation (MAD) and Root Mean Square Error (RMSE) respectively. Metered measurements are generated from possible uncertainties of wind and solar energy profiles which will add-up to $\mathrm{n}$ samples.

$$
\begin{gathered}
R M_{1}=\frac{100 \%}{n} \sum_{q=1}^{n}\left|\frac{E_{c o m}-E_{m e t, q}}{E_{c o m}}\right| \\
R M_{2}=\frac{1}{n} \sum_{q=1}^{n}\left|E_{c o m}-E_{m e t, q}\right| \\
R M_{3}=\sqrt{\frac{\sum_{q=1}^{n}\left(E_{c o m}-E_{m e t, q}\right)^{2}}{n}}
\end{gathered}
$$

\section{Results and Discussion}

The modified CIGRE LV network [36] shown in Fig.7. is used as the test system. A total number of 10 peers are assumed in the system where one of them is a consumer and the remaining nine are prosumers with wind or solar generation. The generation and demand of each peer are given in Fig.7. 


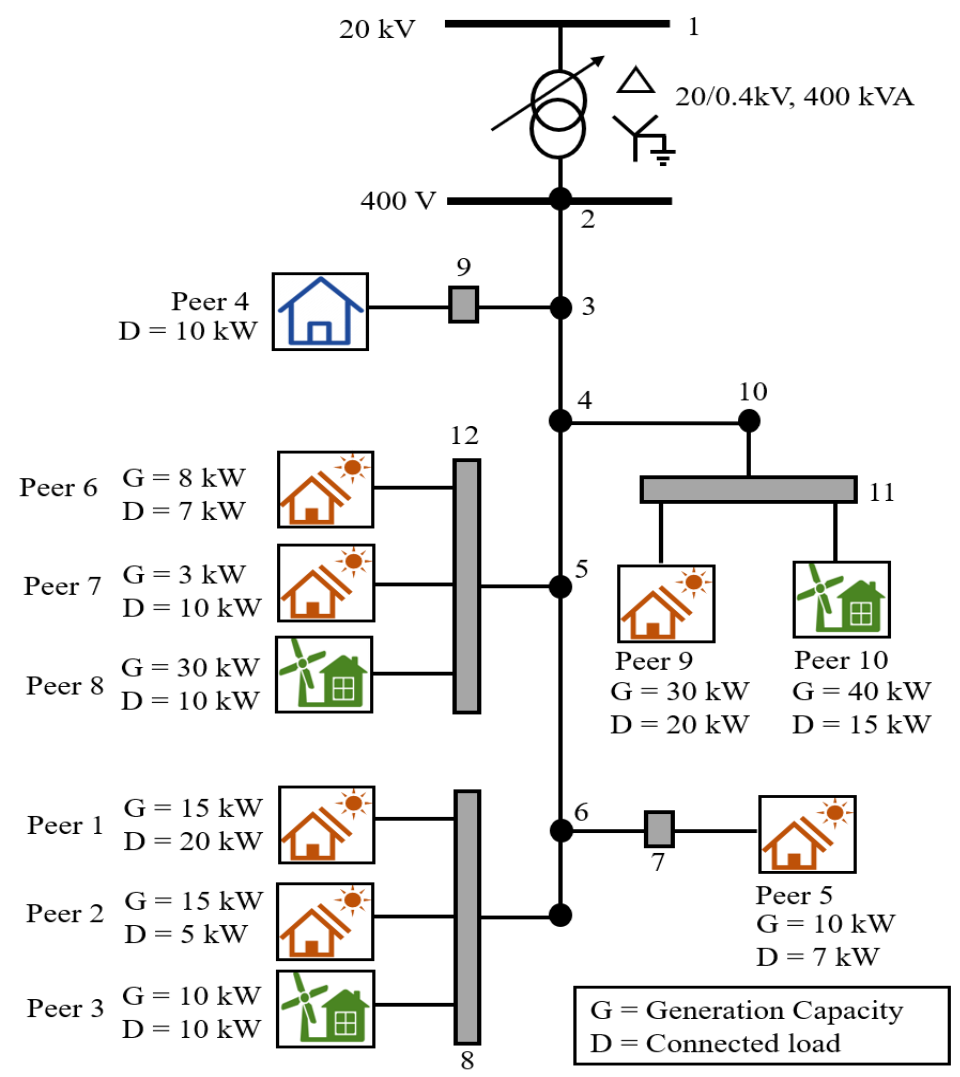

Fig. 7. Modified CIGRE LV system

The hourly load and generation profiles of the system are given in appendices A and B. The time of use tariff and FiTs are shown in Appendix C. The location considered for the study is Cochin, India. Hours 11 to 15 (10:00 AM to 3:00 PM) at which sufficient solar and wind generation is available, is considered for modelling. The one-minute historical data of wind speed and solar irradiation of Cochin is obtained from MERRA data. The maximum possible generation from wind and solar corresponding to the bids ( $G_{\text {wind }}$ and $G_{p v}$ ) and the total demand is shown in Fig.8. The proposed method is validated in MATLAB R2016a that runs on intel core i5 processor at $1.6 \mathrm{GHz}$ and 8 GB RAM. The simulation and tuning parameter values used in SWTCNSPSO are as follows: minimum and maximum values of the control parameter of stochastic trade-off factor are 0.8 and 1.0, lethargy factor $=0.06$, freak factor $=0.06$, population size $=50$, number of iterations $=200$, maximum and minimum accelerated coefficients are 2.5 and 0.5 respectively [34], [35].

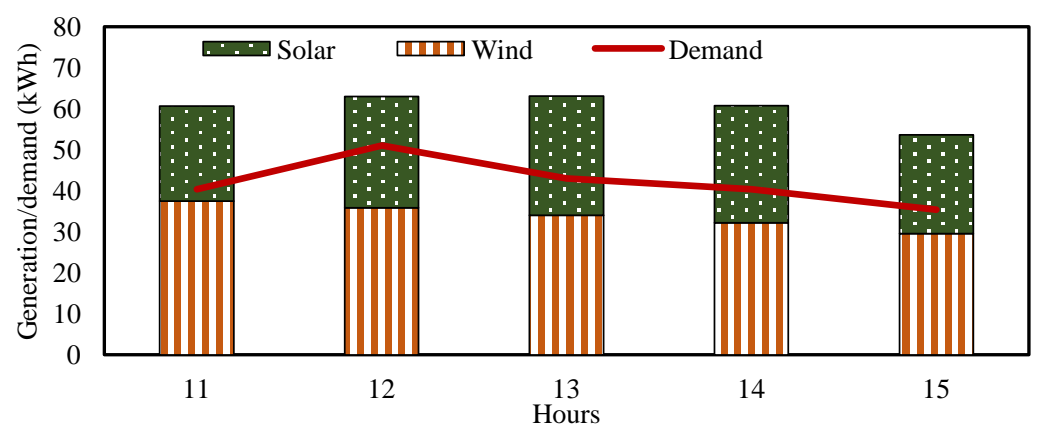

Fig. 8. Maximum possible generation from wind and solar along with load demand 
Effect of location on the efficient frontier: Figures 9 and 10 show the energy return versus energy risk plots for the locations of Cochin and Tiruchirappalli in the $15^{\text {th }}$ hour. The points $O$ and $O^{\prime}$ represent the optimum portfolio corresponding to the maximum value of modified Sharpe ratio given in equation (7) subject to the constraint in equation (6). The corresponding optimum weights for solar and wind generation for Cochin are found to be 0.65 and 0.35 respectively, with a Sharpe ratio of 4.27. But, for Tiruchirappalli, the optimum share of solar is $91 \%$ whereas the proportion of wind is as meagre as $9 \%$ with a Sharpe ratio of 5.18. Also, the length of efficient frontier for Cochin is more, giving the possibility of better mixing of resources against complete dominance of one of them in Tiruchirappalli as shown in Fig. 10. Though there is a reasonable mix of resources in Cochin, the corresponding portfolio energy return for unit risk is found to be lower (based on modified Sharpe ratio). Hence, for locations like Tiruchirappalli, there should be a dominant solar penetration for energy risk adjusted operation. That is, with the right mix of distributed energy resources, we expect more realistic energy commitments from the prosumers adhering to the real time measurements. Henceforth, in this paper, the P2P market studies and settlements are conducted with the data of Cochin only, as it goes better with the generation data given in Fig. 8.

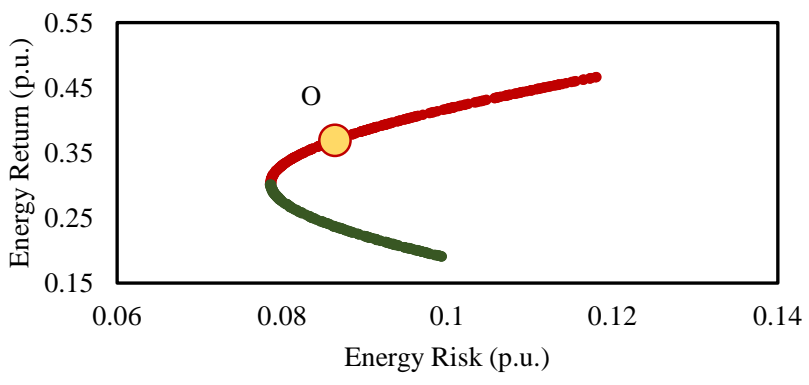

Fig.9. Efficient frontier for Cochin at $15^{\text {th }}$ hour

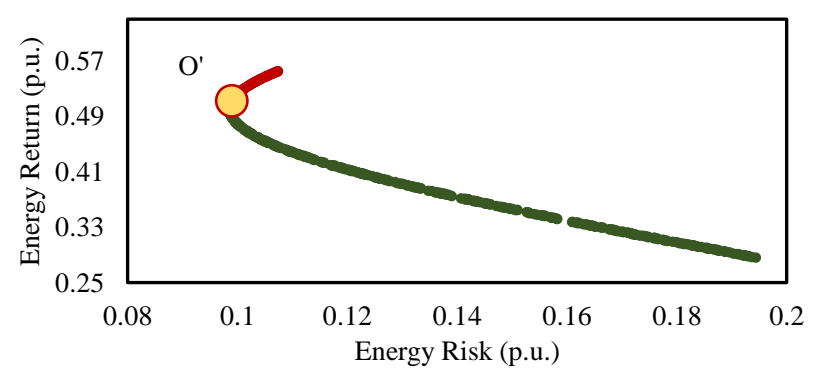

Fig.10. Efficient frontier for Tiruchirappalli at $15^{\text {th }}$ hour

Table. 1. shows the welfare maximized energy portfolio committed in P2P market with and without risk adjustments. Without risk constraints, the total share of solar and wind energy settled is completely governed by the welfare maximization algorithm. Hence, the riskier wind happens to be more $(50 \%-57 \%)$ weighted than solar $(43 \%-50 \%)$ from the welfare point of view. With risk constraints, the proportion of less risky solar is found to be increased.

TABLE. 1. WEIGHTS OF SOLAR AND WIND GENERATION

\begin{tabular}{ccccc}
\hline \multirow{2}{*}{ Hour } & \multicolumn{2}{c}{ Without risk constraint } & \multicolumn{2}{c}{ With risk constraint } \\
\cline { 2 - 5 } & Weight of solar & Weight of wind & Weight of solar & Weight of wind \\
\hline 11 & 0.4991 & 0.5009 & 0.6869 & 0.3131 \\
\hline 12 & 0.4896 & 0.5104 & 0.6651 & 0.3349 \\
\hline 13 & 0.4277 & 0.5723 & 0.6501 & 0.3499 \\
\hline 14 & 0.4699 & 0.5301 & 0.6278 & 0.3722 \\
\hline 15 & 0.4736 & 0.5264 & 0.6552 & 0.3448 \\
\hline
\end{tabular}

Figure 11 shows that the total local generation in the system is always less when considering risk. The non-dominated pareto fronts obtained after welfare maximization using SWTC-NSPSO are shown in Fig. 12. The global compromised solution 
shown in the figure is obtained from the criteria given in equations (17) and (18). Without risk consideration, the higher amount of total energy settled in the market gives a larger welfare to sellers and lower welfare to buyers as seen from the pareto fronts in Fig. 12. In other words, the welfare of sellers is capped and welfare of buyers is imposed a lower limit by the risk constraint. When the energy risk constraint is imposed, the total amount of energy settled in the P2P market is decreased or rather capped at some value. For trading volumes less than this cap, the welfare with and without risk constraint is almost the same whereas the energy volumes beyond this becomes risky. Hence, for the total energy generated, the possibilities/scope for risk-adjusted trading (the proportion of total energy that can be traded in the P2P market considering risk in energy commitment) is limited compared to the risk-prone opportunities.

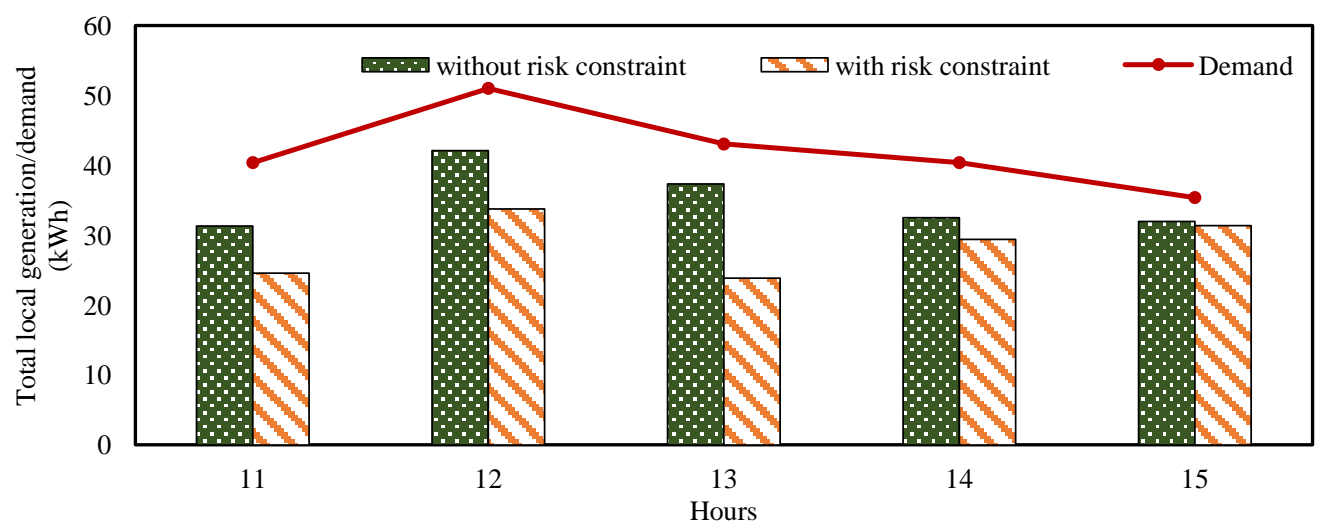

Fig. 11. Total committed generation with and without risk constraint

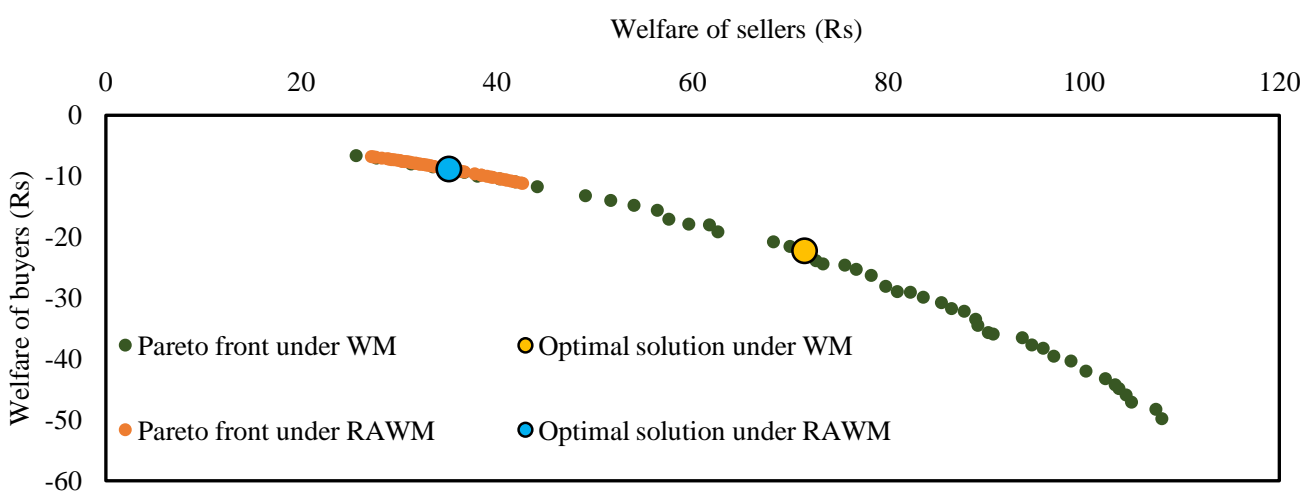

Fig. 12. Pareto fronts obtained after welfare maximization under WM and RAWM

The three risk metric values with and without risk consideration is shown in Table. 2. With the incorporation of risk constraint, all the metric values defined in equations (19), (20), (21) have improved significantly. $\mathrm{RM}_{1}, \mathrm{RM}_{2}$ and $\mathrm{RM}_{3}$ are reduced by almost 70 percentages when considering energy risk. Consequently, the cost incurred for balancing the deviations is reduced as seen from the lower reserve costs in Fig. 13. 
TABLE. 2. COMPARISON OF RISK METRICS

\begin{tabular}{ccccccc}
\hline & \multicolumn{3}{c}{ Without risk constraint } & \multicolumn{3}{c}{ With risk constraint } \\
\cline { 2 - 7 } Hour & $\mathrm{RM}_{1}$ & $\mathrm{RM}_{2}$ & $\mathrm{RM}_{3}$ & $\mathrm{RM}_{1}$ & $\mathrm{RM}_{2}$ & $\mathrm{RM}_{3}$ \\
\cline { 2 - 7 } & $(\%)$ & $(\mathrm{kWh})$ & $(\mathrm{kWh})$ & $(\%)$ & $(\mathrm{kWh})$ & $(\mathrm{kWh})$ \\
\hline 11 & 21.3 & 6.67 & 8.05 & 6.49 & 1.59 & 2.34 \\
\hline 12 & 23.59 & 9.94 & 11.51 & 9.32 & 3.15 & 3.97 \\
\hline 13 & 22.84 & 8.54 & 10.18 & 8.86 & 2.11 & 2.41 \\
\hline 14 & 18.18 & 5.92 & 6.87 & 7.50 & 2.21 & 2.72 \\
\hline 15 & 13.02 & 4.17 & 5.32 & 5.71 & 1.79 & 2.19 \\
\hline
\end{tabular}

Though the value of $\mathrm{RM}_{2}$ at $13^{\text {th }}$ hour is higher than that at $11^{\text {th }}$ hour (Table. 2), the reserve cost is more for $11^{\text {th }}$ hour (Fig. 13) because of the higher tariff rate of Rs. 13/kWh against Rs. 7/kWh (See Appendix C).

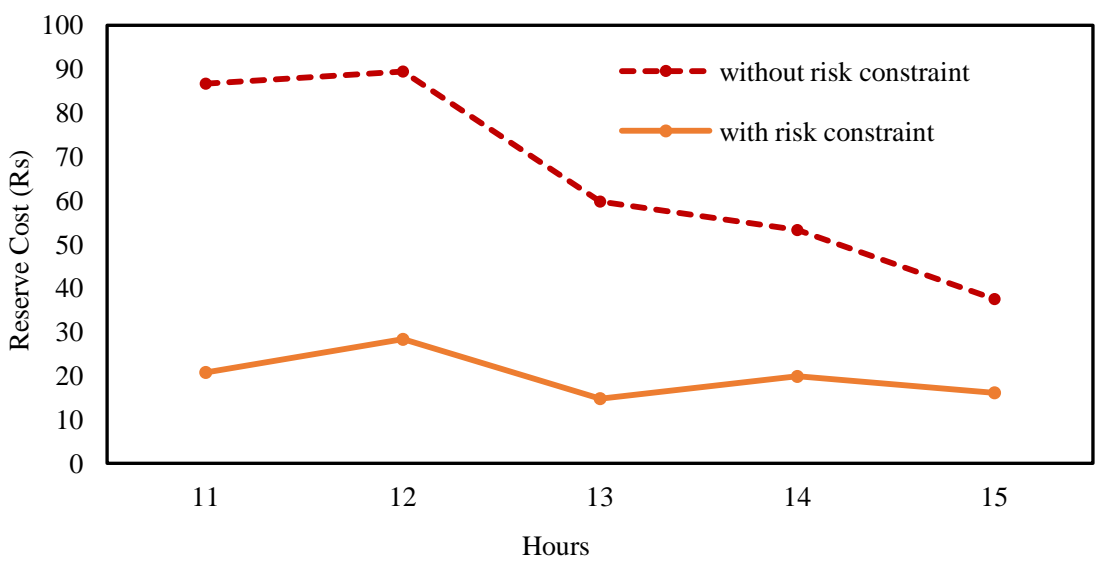

Fig. 13. Reserve cost incurred with and without risk constraints

The peer willingness on expected generation, demand and price is communicated to the third party as shown in Table. 3 . This is based on the wind/solar and load profiles shown in appendices A and B. It is evident that peers 1,3,5,6,8 and 10 are sellers and peers 2,4,7 and 9 are buyers during this hour depending on their energy surplus and deficit shown in Fig. 14. Negative energy represents deficit and positive energy amounts to surplus. Now, based on simple welfare maximization (WM) or energy risk adjusted welfare maximization (RAWM), the final allocated energy would be a proportion of this surplus/deficit. However, a lower proportion is obtained from RAWM. 
TABLE. 3. INPUT FROM PEERS FOR $13{ }^{\mathrm{TH}}$ HOUR

\begin{tabular}{ccccc}
\hline Peers & Generation & Demand & Offer Price & Bid Price \\
& $(\mathrm{kWh})$ & $(\mathrm{kWh})$ & $(\mathrm{Rs} / \mathrm{kWh})$ & $(\mathrm{Rs} / \mathrm{kWh})$ \\
\hline Peer 1 & 7.652 & 1.729 & 2.17 & - \\
\hline Peer 2 & 1.913 & 6.498 & - & 6.96 \\
\hline Peer 3 & 4.254 & 3.282 & 2.29 & - \\
\hline Peer 4 & - & 2.831 & - & 6.27 \\
\hline Peer 5 & 3.826 & 1.469 & 3.76 & - \\
\hline Peer 6 & 3.061 & 2.448 & 2.11 & - \\
\hline Peer 7 & 1.148 & 5.822 & - & 6.88 \\
\hline Peer 8 & 12.763 & 1.635 & 2.83 & - \\
\hline Peer 9 & 11.479 & 14.887 & - & 5.02 \\
\hline Peer 10 & 17.017 & 2.453 & 3.68 & - \\
\hline & & & & \\
\hline
\end{tabular}

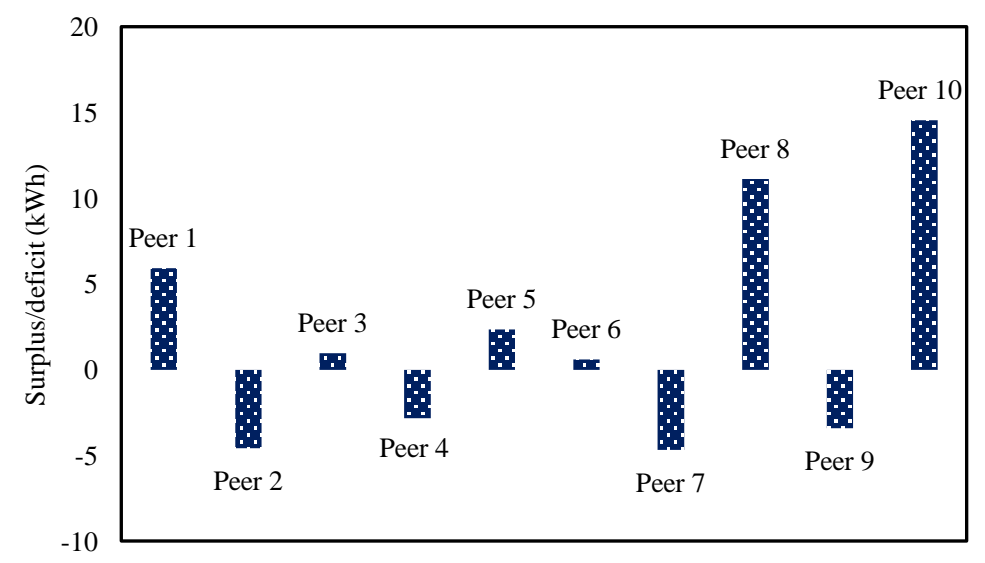

Fig. 14. Surplus/deficit energy of peers

The market clearing price is calculated from the submitted offers/bids as Rs $4.2 / \mathrm{kWh}$ using equation (8). The P2P optimal energy allocation among sellers and buyers in the $13^{\text {th }}$ hour under WM and RAWM is shown in Table. 4. Peer-5 who submitted the highest offer is discarded in WM and peers 4 and 9 with lowest bids are discarded in RAWM based on the energy allocation algorithm given in Section 2.2. The difference is seen in the commitments among peers in accordance with the type of source owned as well. It is seen from Fig. 15 that the shares of peers 1 and 5 with less risky PV dominate in RAWM whereas peers 8 and 10 with riskier wind dominate in WM. Also, the total energy cleared in the P2P market is less in RAWM compared to WM, ensuring minimum deviation between committed and metered transactions. That is, a proportion of total generation is only reliable with respect to the actual availability of resources. For example, in Fig. 16, the willingness submitted by peer-10 
(wind-powered) is $17.01 \mathrm{kWh}$ (his expectation) but his local generation is $8.43 \mathrm{kWh}$ after WM whereas it is $2.64 \mathrm{kWh}$ after RAWM. Finally, the energy committed in the P2P market after meeting his own load is only 200Wh with RAWM. Obviously, a portion of energy from the wind-based peer would be shifted to PV-based peers (1 \& 5) with RAWM as shown in Fig. 15.

TABLE.4. PEER TO PEER ENERGY ALLOCATION OF $13^{\mathrm{TH}}$ HOUR

\begin{tabular}{|c|c|c|c|c|c|}
\hline \multicolumn{2}{|r|}{ Buyers } & Peer 2 & Peer 7 & Peer 4 & Peer 9 \\
\hline \multirow{2}{*}{ Peer 6} & RAWM & 0.1284 & & & \\
\hline & WM & 0.3841 & & & \\
\hline \multirow{2}{*}{ Peer 1} & RAWM & 4.5998 & 0.7968 & - & - \\
\hline & WM & 2.7767 & & & \\
\hline \multirow{2}{*}{ Peer 3} & RAWM & - & 0.4911 & - & - \\
\hline & WM & 0.4250 & & & \\
\hline \multirow{2}{*}{ Peer 8} & RAWM & - & 0.2947 & - & - \\
\hline & WM & 2.3127 & 5.3052 & & \\
\hline \multirow{2}{*}{ Peer 10} & RAWM & - & 0.1911 & - & - \\
\hline & WM & & 0.2094 & 2.8313 & 2.9362 \\
\hline \multirow{2}{*}{ Peer 5} & RAWM & - & 1.9639 & - & - \\
\hline & WM & & & & \\
\hline
\end{tabular}

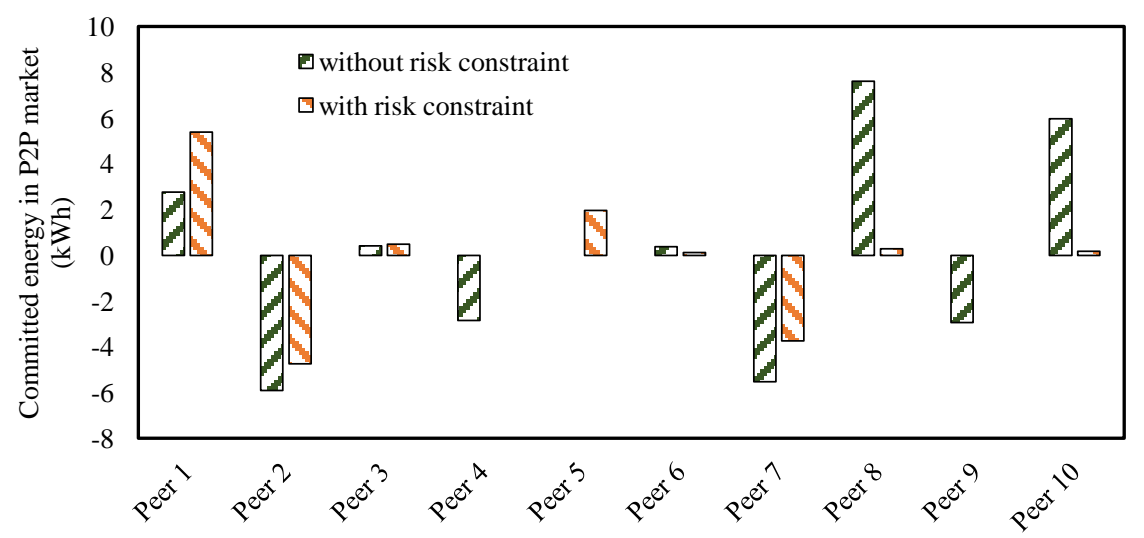

Fig. 15. Committed P2P transactions with and without risk constraint

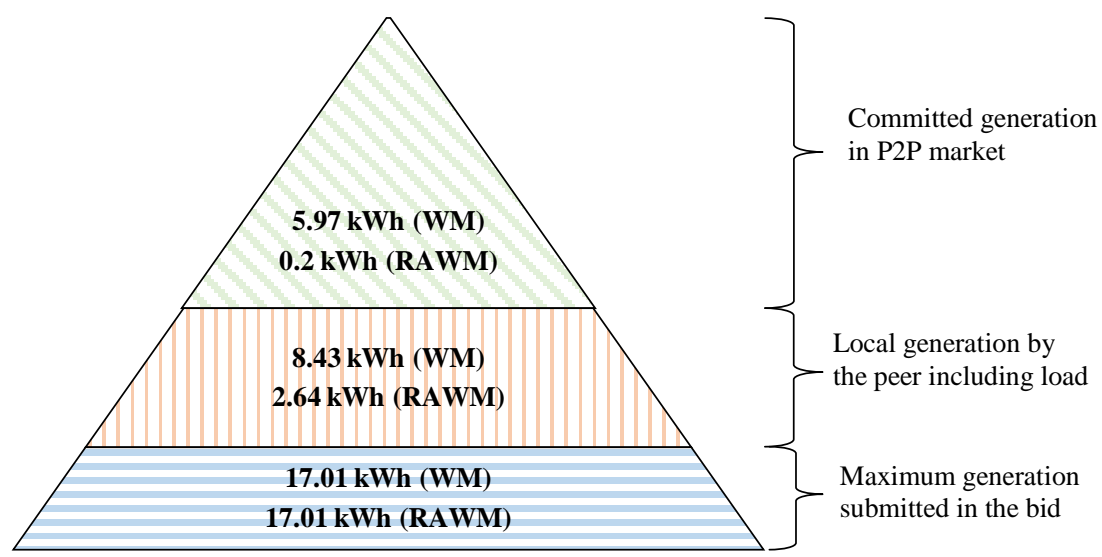


Fig. 16. Energy in offer, optimal local generation and commitment in P2P market of peer-10.

Figures 17 and 18 depict the change in welfare and energy of peers with and without risk consideration. The contribution of welfare from wind-based peers (3, 8 and 10) is found to be $81 \%$ under WM but its share is drastically dipped to $10 \%$ under RAWM. This is compensated by the welfare of solar-based peers (1 and 5) by about $70 \%$. The corresponding shift in energy is evident from Fig. 18 (red color represents solar energy and green represents wind). The shares of total local generation after trading-off the welfare is shown in Fig.18. Peers 4 and 9 are discarded in RAWM where the total energy cleared is less because their incompetent bids couldn't find suitable sellers. With RAWM, the updated energy cap for total wind generation has affected the welfares of peers 8 and 10 compared to peer-3 (See Fig. 17) because of the competent offer price submitted by peer-3 (See Table. 3).

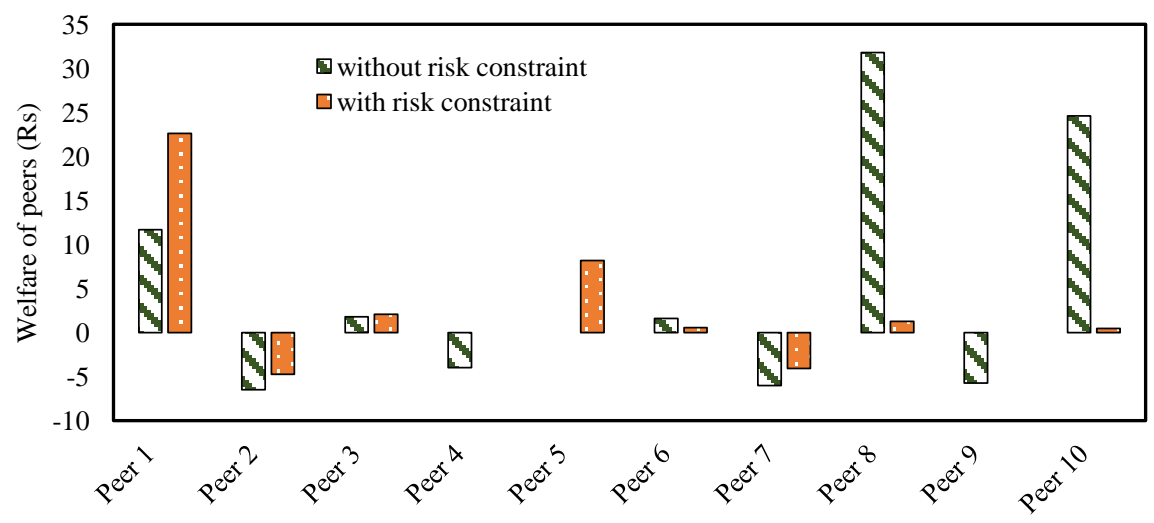

Fig. 17. Welfare of peers with and without risk constraint

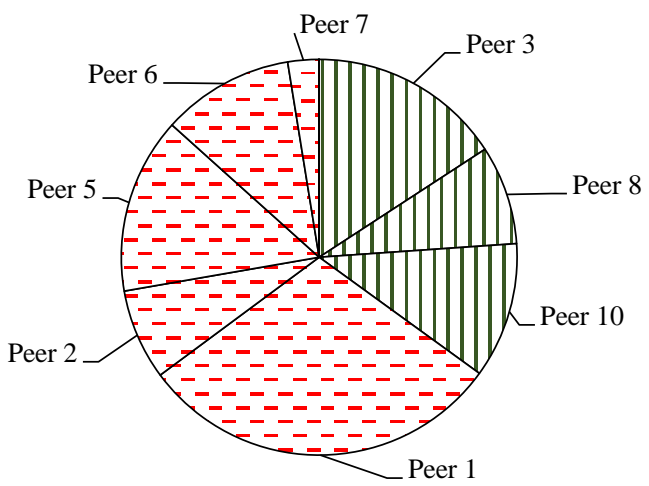

With risk constraints

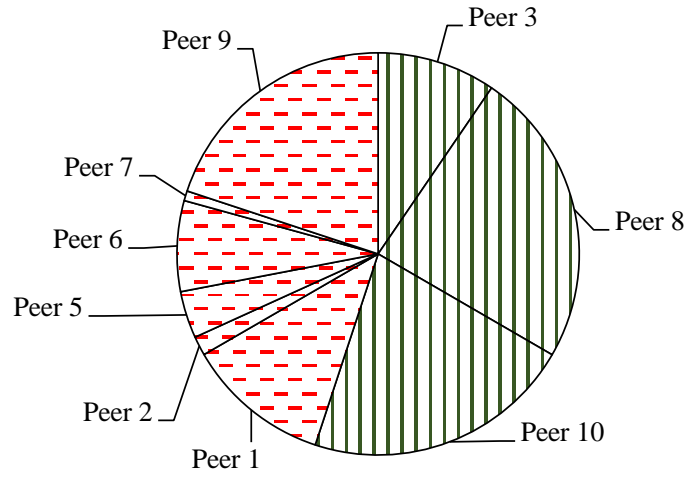

Without risk constraints

Fig. 18. Local generation from peers in WM and RAWM

The comparison of nodal voltage profiles when the same amount of energy is cleared through P2P as well as from the main grid (without local generation) is shown in Fig. 19. In general, the voltage profile is almost nominal because of enough local generation in the system under P2P settlement. For example, the voltage of farthest node 8 is 0.97 p.u. when fed from the grid 
whereas it is improved to 0.998 p.u. with P2P settlement. With P2P transactions, peer-2 buys $54 \%$ of its energy from peers 2 and 3 located at the same node- 8 and remaining from the nearby node- 12 .

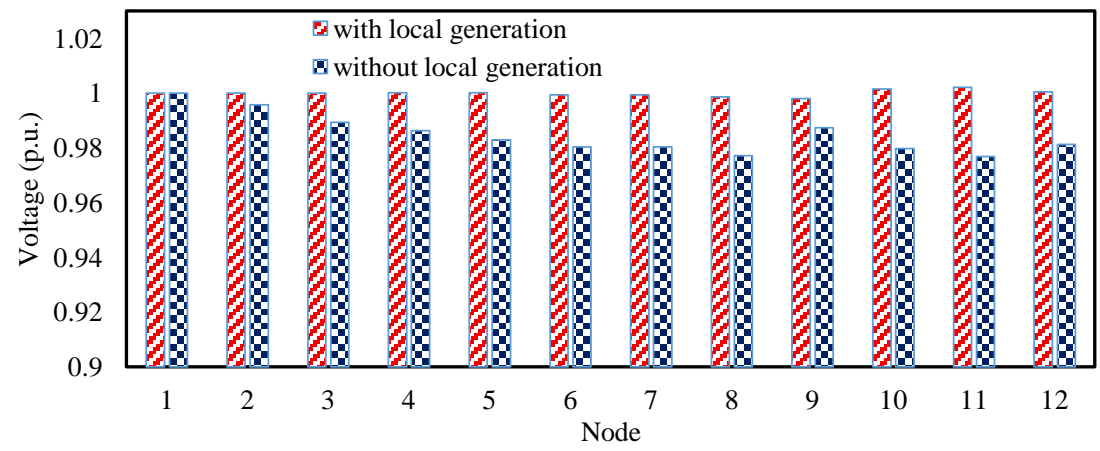

Fig. 19. Nodal voltage profiles with and without local generation

The effect of UoS charge on the distance of energy transaction is compared in Table 5 for the $13^{\text {th }}$ hour. The aggregated energy transacted by the sellers and buyers at each node to the other node, with and without UoS charge is presented in the Table. The node-to-node distance in kilometers is given at the top-right position of each cell. It is evident that the share of energy purchased by peer-2 is more from node-12 (farther) compared to node-8 (nearest own-node) without considering the UoS charge. Also, peers at nodes 11 and 12 predominantly purchase from their own nodes with UoS consideration. Thus, the energy transaction between peers connected to the same node is enhanced whereas farther transactions are diminished with the inclusion of UoS charge which is again evident from the increased own-node transactions at nodes 8, 12 and 11.

TABLE.5. EFFECT OF UoS CHARGE ON TRANSACTION DISTANCE

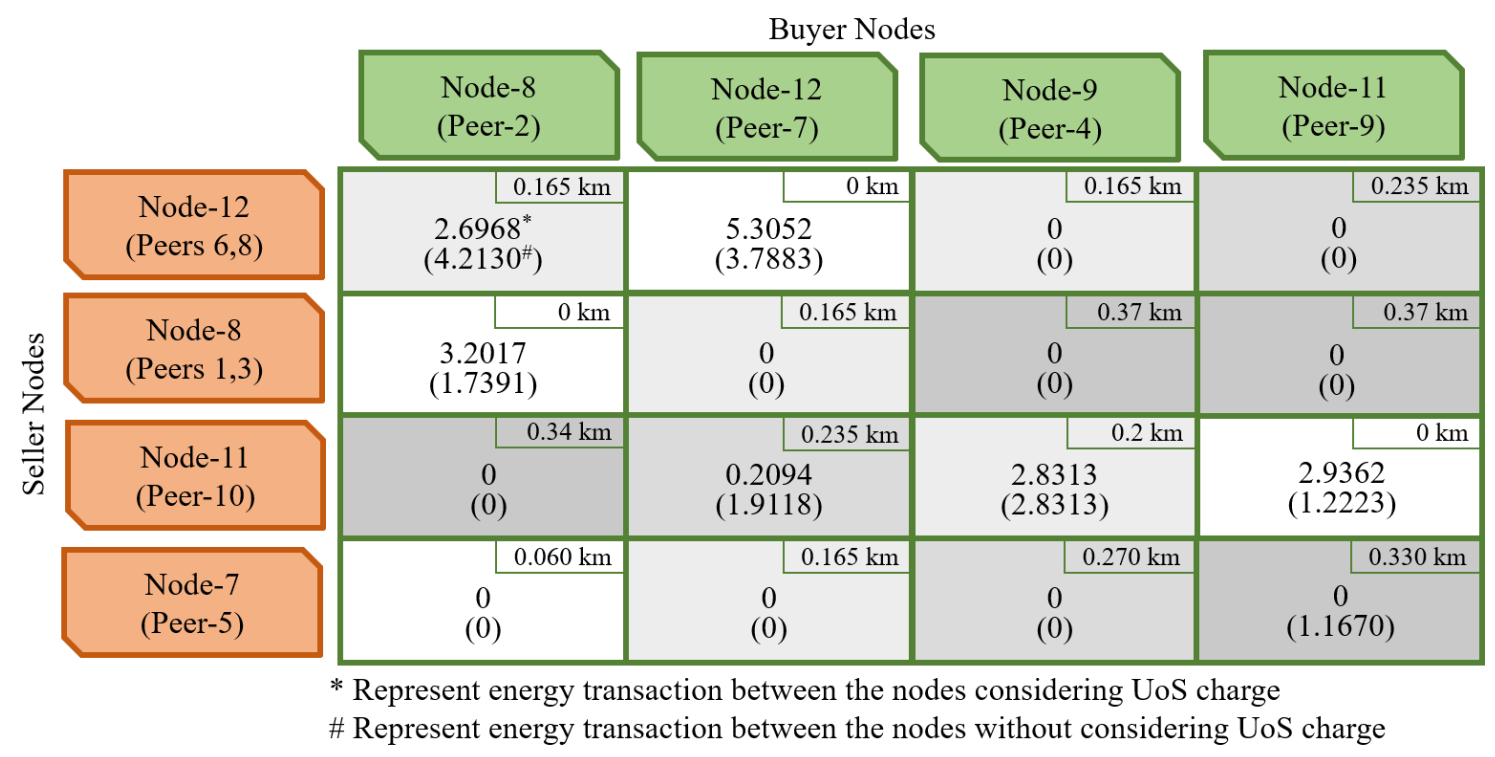

\section{Conclusion}

An energy risk adjusted welfare maximization problem is formulated to obtain more realistic energy commitments from prosumers in the P2P market. The risk model is derived from Markowitz mean-variance portfolio theory and Sharpe ratio. The committed energy in $\mathrm{P} 2 \mathrm{P}$ market is found to be closer to metered measurements based on the defined risk measures derived 
from mean absolute percentage error and deviation. Consequently, the reserve cost is found to be lower for the risk adjusted energy commitments. Also, the conflicting welfares of sellers and buyers are found to be traded-off, subjected to risk and network feasibility constraints, by using SWTC-NSPSO and backward-forward sweep load flow. The optimal peer energy allocation thus obtained is in line with the competence of bid/offer prices submitted, prescribed voltage limits, nature of risk involved in the type of source owned and location of the peer in the network. Further, the service of market conduction and network utilization is charged by the third party based on power transfer sensitivities and total energy cleared. Although the total energy cleared in the P2P market is found to be less with risk adjustments, the energy return per unit risk is higher. The model also recommends having an optimal mix of energy sources in the hourly local generation to facilitate clear-sighted conduction of P2P market. Moreover, the proposed model suggests the local P2P market can be realized in the existing semi-deregulated environment by keeping the distribution operator/owner as a third party 1) for managing the market 2) for ensuring the network feasibility and 3) by paying them a UoS charge.

\section{Appendix A - 24-hour wind and solar generation profile}

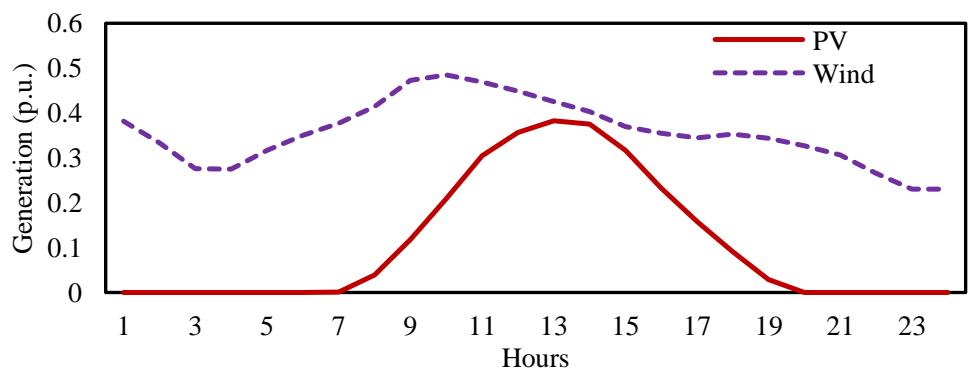

Fig. A.1. Sample solar and wind generation profile of a day

\section{Appendix B - 24-hour load demand profile}

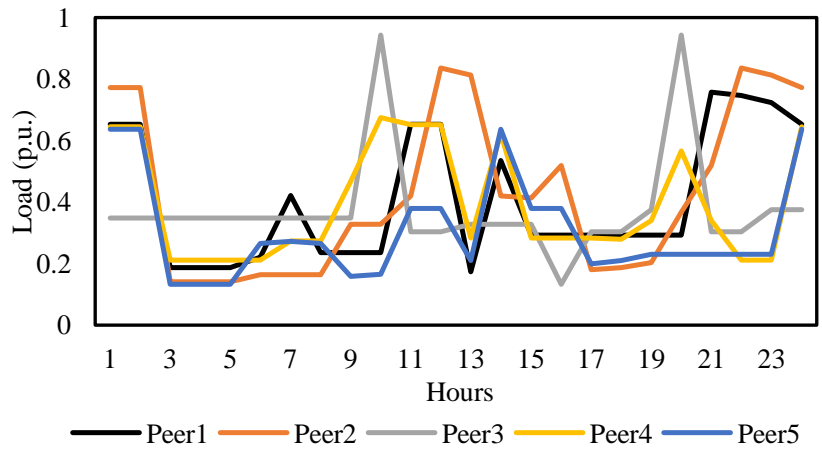

Fig. B.1. Load profiles for peers 1 to 5

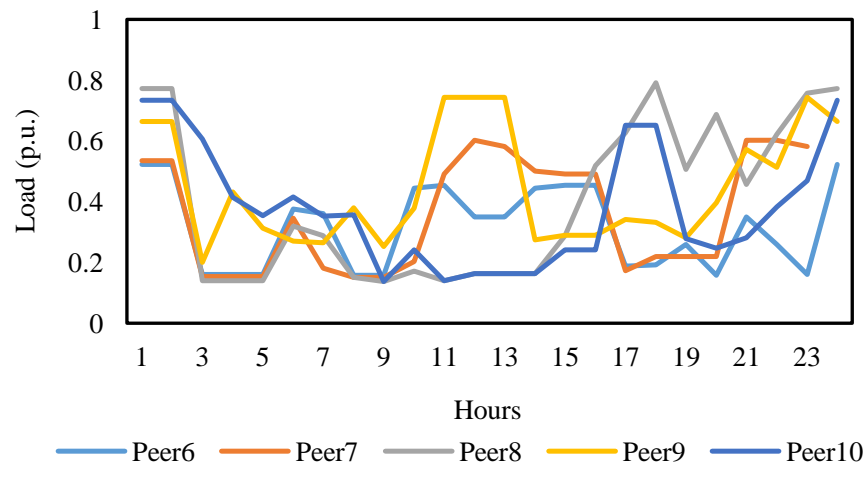

Fig. B.2. Load profiles for peers 6 to 10

\section{Appendix C - Tariff and FiT rates}




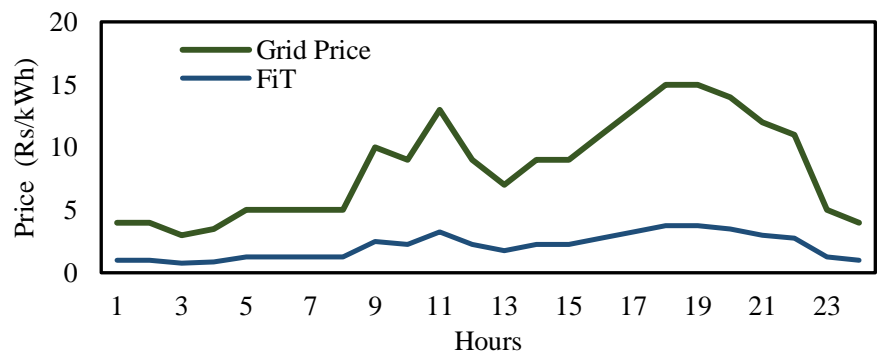

Fig.C.1. 24-hour grid power price and FiT rates

\section{ACKNOWLEDGEMENT}

The authors sincerely acknowledge the financial support provided by SPARC, Ministry of Human Resources and Development, Govt. of India under research Grant No. SPARC/2018-2019/P921/SL dated 15-03-2019 to carry out this work.

\section{REFERENCES}

[1] Y.Parag and B.K. Sovacool, "Electricity market design for the prosumer era", Nature Energy, vol.1, March 2016. https://doi.org/10.1038/nenergy.2016.32.

[2] D.A. López-García, J.P. Torreglosa, D. Vera, "A decentralized P2P control scheme for trading accurate energy fragments in the power grid", International Journal of Electrical Power \& Energy Systems, Volume 110, 2019, Pages 271-282, ISSN 0142-0615, https://doi.org/10.1016/j.ijepes.2019.03.013.

[3] Suyang Zhou, Fenghua Zou, Zhi Wu, Wei Gu, Qiteng Hong, Campbell Booth, “A smart community energy management scheme considering user dominated demand side response and P2P trading", International Journal of Electrical Power \& Energy Systems, Volume 114, 2020, 105378, ISSN 0142-0615, https://doi.org/10.1016/j.ijepes.2019.105378.

[4] S. Xia, S. Bu, C. Wan, X. Lu, K.W. Chan, B. Zhou, "A fully distributed hierarchical control framework for coordinated operation of DERs in active distribution power networks", IEEE Trans. on Power Systems, vol. 34, no. 6, pp. 5184-5197. https://ieeexplore.ieee.org/document/8464285

[5] Daniel L. Donaldson, Dilan Jayaweera, "Effective solar prosumer identification using net smart meter data", International Journal of Electrical Power \& Energy Systems, Volume 118, 2020, 105823, ISSN 0142-0615, https://doi.org/10.1016/j.ijepes.2020.105823.

[6] Vivek Mohan, Jai Govind Singh, Weerakorn Ongsakul, "An efficient two stage stochastic optimal energy and reserve management in a microgrid", Applied Energy, Volume 160, 2015, Pages 28-38, ISSN 0306-2619. https://doi.org/10.1016/j.apenergy.2015.09.039.

[7] Mohan, Vivek \& Singh, Jai Govind \& Ongsakul, Weerakorn, "Sortino Ratio Based Portfolio Optimization Considering EVs and Renewable Energy in Microgrid Power Market”, IEEE Transactions on Sustainable Energy, 2016. https://doi:10.1109/TSTE.2016.2593713.

[8] David C. Rode, Paul S. Fischbeck, "Reduced-form models for power market risk analysis", Applied Energy, Volume 228, 2018, Pages 16401655,ISSN 0306-2619. https://doi.org/10.1016/j.apenergy.2018.07.044.

[9] M.S. Li, Z.J. Lin, T.Y. Ji, Q.H. Wu, "Risk constrained stochastic economic dispatch considering dependence of multiple wind farms using paircopula”, Applied Energy, Volume 226, 2018, Pages 967-978, ISSN 0306-2619. https://doi.org/10.1016/j.apenergy.2018.05.128

[10] Nan Shang, Chengjin Ye, Yi Ding, Teng Tu, Baofeng Huo, "Risk-based optimal power portfolio methodology for generation companies considering cross-region generation right trade”, Applied Energy, Volume 254, 2019, 113511, ISSN 0306-2619. https://doi.org/10.1016/j.apenergy.2019.113511.

[11] Hongye Guo, Qixin Chen, Qing Xia, Chongqing Kang, "Electricity wholesale market equilibrium analysis integrating individual risk-averse features of generation companies”, Applied Energy, Volume 252, 2019, 113443, ISSN 0306-2619. https://doi.org/10.1016/j.apenergy.2019.113443.

[12] Shantanu Chakraborty, Tim Baarslag, Michael Kaisers, "Automated peer-to-peer negotiation for energy contract settlements in residential cooperatives", Applied Energy, Volume 259, 2020, 114173, ISSN 0306-2619. https://doi.org/10.1016/j.apenergy.2019.114173. 
[13] Y. Liu, L. Xiao, G. Yao and S. Bu, "Pricing-based demand response for a smart home with various types of household appliances considering customer satisfaction", IEEE Access, vol. 7, pp. 86463-86472. https://ieeexplore.ieee.org/document/8742540

[14] Kaixuan Chen, Jin Lin, Yonghua Song, "Trading strategy optimization for a prosumer in continuous double auction-based peer-to-peer market: A prediction-integration model”, Applied Energy, Volume 242, 2019, Pages 1121-1133, ISSN 0306-2619. https://doi.org/10.1016/j.apenergy.2019.03.094.

[15] G. De Zotti, S. A. Pourmousavi, H. Madsen and N. Kjølstad Poulsen, "Ancillary Services 4.0: A Top-to-Bottom Control-Based Approach for Solving Ancillary Services Problems in Smart Grids", in IEEE Access, vol. 6, pp. 11694-11706, 2018. https://doi:10.1109/ACCESS.2018.2805330.

[16] Nand K. Meena, Jin Yang, Evan Zacharis, "Optimisation framework for the design and operation of open-market urban and remote community microgrids", Applied Energy, Volume 252, 2019, 113399, ISSN 0306-2619, https://doi.org/10.1016/j.apenergy.2019.113399.

[17] E. Mengelkamp, J.Gärttner, K.Rock, S.Kessler, L.Orsini, C.Weinhardt, "Designing microgrid energy markets: A case study: The Brooklyn Microgrid”, Applied Energy, Volume 210, 2018, Pages 870-880, ISSN 0306-2619. https://doi.org/10.1016/j.apenergy.2017.06.054.

[18] M.Andoni, V.Robu, D.Flynn, S.Abram, D.Geach, D.Jenkins, P.McCallum, A.Peacock, "Blockchain technology in the energy sector: A systematic review of challenges and opportunities", Renewable and Sustainable Energy Reviews, Volume 100, 2019, Pages 143-174, ISSN 1364-0321, https://doi.org/10.1016/j.rser.2018.10.014.

[19] H. Pourbabak, Tao Chen and W. Su, "Consensus-based distributed control for economic operation of distribution grid with multiple consumers and prosumers", IEEE Power and Energy Society General Meeting (PESGM), Boston, MA, pp. 1-5. 2016. https://doi:10.1109/PESGM.2016.7741083.

[20] Shuangrui Yin, Qian Ai, Zhaoyu Li, Yufan Zhang, Tianguang Lu, "Energy management for aggregate prosumers in a virtual power plant: A robust Stackelberg game approach", International Journal of Electrical Power \& Energy Systems, Volume 117, 2020, 105605, ISSN 0142-0615, https://doi.org/10.1016/j.ijepes.2019.105605.

[21] A. Paudel, K. Chaudhari, C. Long and H. B. Gooi, "Peer-to-Peer Energy Trading in a Prosumer-Based Community Microgrid: A Game-Theoretic Model", in IEEE Transactions on Industrial Electronics, vol. 66, no. 8, pp. 6087-6097, Aug. 2019. https://doi:10.1109/TIE.2018.2874578.

[22] W. Tushar, T. K. Saha, C. Yuen, P. Liddell, R. Bean and H. V. Poor, "Peer-to-Peer Energy Trading with Sustainable User Participation: A Game Theoretic Approach", in IEEE Access, vol. 6, pp. 62932-62943, 2018.

[23] Khorasany Mohsen \& Mishra Yateendra \& Ledwich Gerard, “A Decentralised Bilateral Energy Trading System for Peer-to-Peer Electricity Markets”, IEEE Transactions on Industrial Electronics, 2019. https://doi:10.1109/TIE.2019.2931229.

[24] M. Khorasany, Y. Mishra, and G. Ledwich, "Auction Based Energy Trading in Transactive Energy Market with Active Participation of Prosumers and Consumers", In Proc. Australian Universities Power Engineering Conf. (AUPEC), Melbourne, pp.1-6, 2017. https://doi:10.1109/AUPEC.2017.8282470.

[25] P. Bajpai and S. N. Singh, "An electric power trading model for Indian electricity market", 2006 IEEE Power Engineering Society General Meeting, Montreal, Que., 2006. https://doi:10.1109/PES.2006.1709055.

[26] Kumar, S. \& Bhattacharyya, Biplab \& Gupta, Vikash, "Present and Future Energy Scenario in India”, Journal of The Institution of Engineers, India, 2014. https://doi.org/10.1007/s40031-014-0099-7.

[27] Tamilnadu Solar Energy Policy 2019. [online]. Available at http://teda.in/wp-content/uploads/2019/02/SOLARPOLICY2019.pdf.

[28] Grid Connected Rooftop Solar Power Projects under Ministry of New and Renewable Energy, Government of India. [online]. Available at https://mnre.gov.in/solar-rooftop-grid-connected.

[29] H. Markowitz, "Portfolio selection", The Journal of Finance, Vol. 7, No. 1, pp. 77-91, (1952).

[30] West G, “An Introduction to Modern Portfolio Theory: Markowitz, CAP-M, APT and Black-Litterman,” Financial Modelling Agency, 2006.

[31] Sharpe William F, “The Sharpe Ratio,” The Journal of Portfolio Management ,1994. 
[32] B. Chai, J. Chen, Z. Yang and Y. Zhang, "Demand Response Management with Multiple Utility Companies: A Two-Level Game Approach", in IEEE Transactions on Smart Grid, vol. 5, no. 2, pp. 722-731, March 2014. https://doi:10.1109/TSG.2013.2295024.

[33] E. Bompard, E. Carpaneto, G. Chicco, and R. Napoli, "Convergence of the backward/forward sweep method for the load-flow analysis of radial distribution systems", Int. J. Electr. Power Energy Syst., vol. 22, no. 7, pp. 521-530, Oct. 2000. https://doi.org/10.1016/S0142-0615(00)00009-0.

[34] A. Man-Im, W. Ongsakul, J. G. Singh and C. Boonchuay, "Multi-objective optimal power flow using stochastic weight trade-off chaotic NSPSO", IEEE Innovative Smart Grid Technologies - Asia (ISGT ASIA), Bangkok, 2015, pp. 1-8. https://doi:10.1109/ISGT-Asia.2015.7387120.

[35] A. Man-Im, W. Ongsakul, J. G. Singh and C. Boonchuay, "Multi-objective Economic Dispatch Considering Wind Power Penetration Using StochasticWeight Trade-off Chaotic NSPSO”, Electric Power Components and Systems., 2017. https://doi:10.1080/15325008.2017.1362067.

[36] Papathanassiou S, Hatziargyriou N, Strunz K. “A benchmark low voltage microgrid network”, CIGRE Symp Power Syst with dispersed Gener Technol impact Dev Oper performances, Athens, Greece; 2005. p. 1-8. 